\title{
Interannual Variations in Simulated and Observed MSU-2 Temperatures
}

J.S. Boyle

\section{August 16, 2000}

U.S. Department of Energy

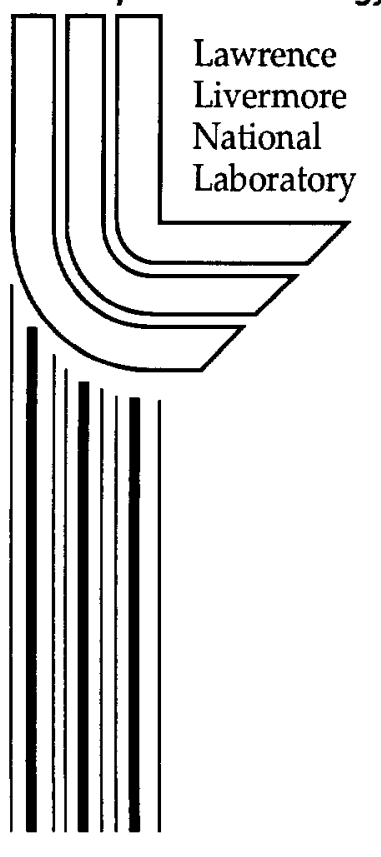




\section{DISCLAIMER}

This document was prepared as an account of work sponsored by an agency of the United States Government. Neither the United States Government nor the University of California nor any of their employees, makes any warranty, express or implied, or assumes any legal liability or responsibility for the accuracy, completeness, or usefulness of any information, apparatus, product, or process disclosed, or represents that its use would not infringe privately owned rights. Reference herein to any specific commercial product, process, or service by trade name, trademark, manufacturer, or otherwise, does not necessarily constitute or imply its endorsement, recommendation, or favoring by the United States Government or the University of California. The views and opinions of authors expressed herein do not necessarily state or reflect those of the United States Government or the University of California, and shall not be used for advertising or product endorsement purposes.

This work was performed under the auspices of the U. S. Department of Energy by the University of California, Lawrence Livermore National Laboratory under Contract No. W-7405-Eng-48.

This report has been reproduced directly from the best available copy.

Available electronically at http://www.doe.gov/bridge

Available for a processing fee to U.S. Department of Energy

and its contractors in paper from

U.S. Department of Energy

Office of Scientific and Technical Information

P.O. Box 62

Oak Ridge, TN 37831-0062

Telephone: (865) 576-8401

Facsimile: (865) 576-5728

E-mail: reports@adonis.osti.gov

Available for the sale to the public from

U.S. Department of Commerce

National Technical Information Service

5285 Port Royal Road

Springfield, VA 22161

Telephone: (800) 553-6847

Facsimile: (703) 605-6900

E-mail: orders@ntis.fedworld.gov

Online ordering: http://www.ntis.gov/ordering.htm

\section{OR}

Lawrence Livermore National Laboratory

Technical Information Department's Digital Library

http://www.llnl.gov/tid/Library.html 


\title{
Interannual variations in simulated and observed MSU-2 temperatures
}

\author{
by \\ James S. Boyle \\ Program for Climate Model Diagnosis and Intercomparison \\ Lawrence Livermore National Laboratory \\ Livermore, CA USA
}

August 2000 



\section{Abstract}

Microwave Sounding Unit (MSU) channel 2 temperatures are computed for three sets of model experiments and their interannual variation is compared to that of the observed. The models used are: (1) an ensemble of ten integrations of the NCAR CCM3 using prescribed SSTs for 1979 to 1995, (2) A 300 year integration of the NCAR/DOE Parallel Climate Model (which has the CCM3 as the atmospheric model) and (3) a 300 year integration of the ECHAM4/OPYC coupled model at the Max Planck Institute for Meteorology. In addition Nino34 and AO indices were computed from SST and MSLP of each data set.The observed data spanned the period of 1979 to 1998 . The CCM3 integrations used the observed SSTs from 1979 to 1995 . The 300 year coupled runs were divided into non-overlapping 20 year segments and each segment was processed independently.

The EOFs of the zonally averaged, monthly mean MSU-2 anomalies were computed. An SVD analysis of the covariance of the tropical (30S-30N) precipitation and MSU-2 was carried out.

The first and second mode of the observations are related to the ENSO variations and the Arctic Oscillation, respectively. The Nino34 index leads the ENSO mode by 5 months in the observations. For the nine realizations of the CCM3, all have the ENSO as the leading mode but one does not have the $\mathrm{AO}$ as the second. The lag between the Nino34 and leading EOF decreases to about 3 months. The fourteen PCM 20 year segments show a similar variation to the CCM3, but the lag is decreased to 2 months. All fourteen of the ECHAM segments have the ENSO and AO as the leading and second modes. The fourteen ECHAM data sets evince smaller variations between segments than the PCM and even the CCM3 realizations. The lag between the ECHAM Nino34 and the leading EOF is about 3 months.Thus, both coupled models have a substantially faster response to variations in tropical SSTs. This can affect the way that these models simulate the relation between the seasonal cycle and ENSO. 



\section{Introduction}

This paper compares the brightness temperatures measured by the Microwave Sounding Unit (MSU) channel $2(53.74 \mathrm{GHz})$ to the analogous brightness temperatures computed from General Circulation Model (GCM) output. Specifically, we are investigating the interannual variation of the monthly means of the brightness temperature. The MSU-2 data are available for 20 years, 1979 to 1998, and form a global measurement of the mean temperature of the lower $80 \%$ of the atmosphere. Since we are interested in the interannual variations the problems associated with estimating trends from these data, Hurrel and Trenberth (1997), are not pertinent. Although the 20 years is a rather short record it is felt that in should be adequate to indicate the patterns of the major modes of interannual variation.

A work addressing the relation of MSU temperatures and tropical SST variations was that of Newell and Wu (1992). They established the close relation of MSU and SST temperatures in the Tropics. There was a clear ENSO signal of the variations of the MSU values. The entire tropical band reacted in a nearly uniform fashion to the ocean forcing. They noted lags of up to 6 months between the SSTs in the Tropical eastern pacific and the MSU anomalies. In the extratropics the relations were restricted locally and to lags of only a month.

Yulaeva and Wallace (1994), hereafter YW, described the ENSO signature in the MSU data. They identified two components of the MSU response, anomalies in the mean temperature and a residual which consisted of the zonally asymmetric part of the ENSO signature. A key to this decomposition was the 3 month time lag between the two components. The residual component was identified with the dynamical response to the changes in convection over the equatorial central Pacific. The mean tropical temperature was shown to be consistent with a thermodynamic response to the surface energy fluxes driven by the SST anomalies in the equatorial eastern $\mathrm{Pa}$ cific. The mean temperature displayed the 1 to 2 season lag with respect to the SSTs as seen in Newell and Wu (1992).

It would appear to be a useful check on the model physics and especially the air sea interactions, that they correctly model the relationships between tropical SSTs and MSU2 temperatures. The model data used here is from integrations using prescribed SST and from fully coupled ocean/atmosphere GCMs While one would certainly not expect the coupled models to reproduce the observed MSU-2 record, it is 
reasonable to assume that the leading modes of variability of the MSU data be reflected in the model integrations.

The next section will present the data both observed and model. The next section contains the results of the EOF analysis of zonally averaged MSU2 temperatures, The zonal mean was used in order to provide more spatial information than just the global mean but also accomplish enough data condensation to compare a large number of data sets. Section 3 is an SVD analysis of the covariance of tropical precipitation and MSU2 temperature.The final section will be discussion and conclusions.

\section{Data and data procedures}

\section{a. Observed Data}

The MSU data were obtained from the web site maintained by John Christy at the University of Alabama Huntsville. These data have been processed to provide a continuous record from 1979 to 1998, Spencer and Christy (1992). The MSU-2 data represent a weighted tropospheric mean temperature. The weighting curve has a maximum near $500 \mathrm{hPa}$. The curve is provided in Hurrel and Trenberth (1999). The data are on a global $2.5 \times 2.5$ degree longitude, latitude grid.

The precipitation data used here was that described by Xie and Arkin (1992).It represents a blending of gauge measurements and satellite estimates of precipitation put on a global $2.5 \times 2.5$ degree longitude latitude grid.

\section{b. Model Data}

Data was available for an ensemble of ten realizations of the NCAR Community Climate Model, version 3, Kiehl et al. (1998). These all used identical, prescribed observed SSTs but varied slightly in the initial conditions. The first of these integrations is the NCAR CCM3 submission to AMIP2. The integrations used observed SSTs from 1979 to 1994 as specified by the AMIP2 protocol.

A coupled GCM integration which used the CCM3 as its atmospheric model is the NCAR/DOE Parallel Climate Model (PCM), Washington and Coauthors (2000),The PCM data used here consisted of a 300 year control integration using present day conditions of greenhouse gases. This is a fully coupled air-land-ocean-sea ice model. Finally, data was obtained for the ECHAM 4 /OPYC (ECHAM), Roeckner et al. $(1999)$,300 year integration of present day conditions. These data were provided by the Max Planck Institute for Meteorology in Hamburg. 
From each 300 year integration of ECHAM and PCM, non-overlapping 20 year periods were processed computing the MSU2 temperatures and the interannual anomalies. To minimize any possible spinup problems the initial 20 year segment of each model was not used.

The nature of the tropical SST variations in the NCAR/DOE Parallel Climate Model and the ECHAM 4 /OPYC integrations is fairly realistic. Figure 1 presents a frequency distribution of SST anomalies for the Nino3.4 region, 5S-5N, 170W-120W, for both models and observations. The observations are only for the period 1950 to 1999, while the model data are for 280 years of simulation. The frequencies are normalized. Overall, the models do a credible job in emulating the SST variations in this region. The ECHAM model has a definite tendency to have fewer of the large positive anomalies, a trait shared to a lesser extent by the PCM. Both models tend to look more like the observations for the cold anomalies. Over the past twenty years the SST variations in the tropical Pacific have been rather remarkable, so the models may be a bit better than Fig. 1 might indicate. If 280 years of observations existed they might well look more like the model data.

\section{c. Calculation of MSU Brightness temperatures}

All the GCM MSU-2 brightness temperatures were generated using a weighting function supplied by John Christy and following procedures outlined in Hurrel and Trenberth (1999). The computation is simply determining the weighted vertical mean of the model's temperature field for each grid point of the monthly mean values. Temperature values at grid points where the pressure level was below the model terrain surface for the entire month were not used in the calculation.

d. Arctic Oscillation and Nino3.4 Indices

The Arctic Oscillation (AO) index was computed as described in Thompson and Wallace(2000) as the leading principal component of the MSLP over all longitudes from $20 \mathrm{~N}$ to $90 \mathrm{~N}$. The observed AO was computed using the MSLP of the NCEP/ NCAR reanalysis for the period 1979 to 1997 . The index computed this way was virtually identical to that made available by Thompson and Wallace.

The Nino 3.4 index was computed as indicated by Barnston et al. (1997). This is an average of the SST in the region $5 \mathrm{~S}-5 \mathrm{~N}, 170 \mathrm{~W}-120 \mathrm{~W}$. The SSTs were available for all the models and observations, the same code was used to compute all the Nino3.4 mean temperature anomalies. 


\section{Results}

\section{a. EOFs of Zonal mean anomalies and correlations with Indices}

Figure 2a shows the leading two EOFs of the covariance matrix of zonally averaged MSU-2 monthly mean anomalies for the period 1979 to 1998. As seen in Table 1 , this second mode is fairly well separated from the third. The first mode is quite similar to the one presented by YW, only they used data for the period 1979 to 1992 . The leading mode is obviously dominated by tropical variability, while the second is confined to the northern extratropics. Figure $2 \mathrm{~b}$ presents the lagged correlation of the leading mode's expansion coefficients and the Nino3.4 ocean temperature anomalies. As might be anticipated, the leading mode displays a strong correlation to the Nino3.4 index. The maximum of about 0.7 is lagged at 5 months, the SST variation leading the MSU mode. This lag of 1-2 seasons is a robust feature of the relation of mean tropospheric temperature and the Tropical pacific SST, Newell and Wu (1992), Hurrel and Trenberth (1992), YW. The broad nature of the lagged correlation curve shows the long time scale of the interaction of the global atmosphere and the tropical Pacific. In Fig. 2c, the second mode shows a simultaneous correlation maximum with the $\mathrm{AO}$ index, and a rapid falloff on either side, as compared to the gentle fall of the previous figure. Thus, the two leading EOF modes can be related to the ENSO and AO oscillations for the period. This neatly encapsulates two of the major modes of interannual variability in a single analyses, and as such presents a metric for the evaluation of this aspect of atmospheric and atmosphere-ocean GCMs. The sixth EOF displayed a similar correspondence to the Southern Hemisphere High Latitude Mode, Kidson(1988), as the second did to the $\mathrm{AO}$ index. This mode accounted for about $5 \%$ of the variance, it was felt that this level of variance was too low for any further investigation in this work.

Figure 3 is the same as Fig. 2, except for the MSU2 temperatures computed for the CCM3 AMIP2 integration. The sequence of figures in the Fig. 2, the observations, and Fig. 3, the CCM3, is quite similar. From Table 1, it can be seen that the explained variance is comparable to the observations. The lag correlation plot of the leading mode with the Nino34 SST, Fig. 3b, reaches the maximum a bit quicker than seen in the observations. The peak is at 3 months, as opposed to 5 . The value of the correla-

tion maximum being about the same at 0.7 . The second mode has a maximum at zero 
lag with the $\mathrm{AO}$ index as in the observations, but the peak correlation value is somewhat reduced in the model result. The model appears to be behaving in a manner much like the observed atmosphere except the ENSO forcing of the mean tropospheric temperature is proceeding faster.

We are restricted to one realization of the observed atmosphere, but this does not apply to the model. Multiple realizations are especially vital to gain the proper perspective when dealing with variability as opposed to mean climate. The same EOF analysis was carried out for 10 realizations of the CCM3. Table 1 shows that the percent variance of the leading mode does vary a fair bit across the various realizations, and the distinction of mode two and three can be small. The leading mode, associated with ENSO, is always well separated and dominant. Figure 4 displays the same data as in Fig. 3 except for the ten realizations of the CCM3 plotted together and the leading and second modes are displayed on separate figures. Figure $4 \mathrm{a}$, the leading mode, shows that the region in the Tropics, $30 \mathrm{~S}-30 \mathrm{~N}$, has a reproducible pattern while poleward of this region the inter-realization variability is large. The variations in the midlatitudes have little synchronicity with the Tropics and are not restrained to any great extent by the imposed SSTs. The lag correlation with the Nino3.4 time series, Fig. $4 c$, shows a good deal of consistency between the realizations. The lag to the peak in the correlation varies from 3 to 5 months, with 3,6 and 1 being the number of realizations for lags of 3,4 and 5 months, respectively. While the model can match the lag seen in the observations(in one case), it does tend towards shorter lags. Figure $4 \mathrm{~d}$ shows that at least one and probably two realizations do not have an $\mathrm{AO}$ related mode as the second.

Figure 5 displays the leading modes and lag correlations for the EOF analysis of the zonally averaged MSU2 temperatures of fourteen 20 year segments of the PCM integration.Table 2 lists the percent variance explained for the leading four modes. The atmospheric model used in these fully coupled simulations is the same version of the CCM3 as analyzed above. Figure 5a appears to have more variation than Fig. 4a, which might just be due to the fact that there are 5 more data sets in the PCM figures. A more likely cause is that the PCM would exhibit more variation in the Tropics since the SST anomalies are unique for each 20 year section, whilst they are the identical for each member of the CCM3 ensemble. As seen in Table 2, the percent variance explained by the leading mode tends to drop compared to the CCM3 and observations, yet there are segments with comparable values. The range of the leading percent vari- 
ance explained is somewhat larger than in Table 1 among the CCM3 AMIP ensemble. It is also evident from Table 2 that the second and third modes are not always well separated. Figure 5c reveals that the coupled model accentuates the shortening lag indicated by the CCM3 runs. Eleven of the PCM sections have maximum correlation at lags of 2 months and 3 have lags of 3 months. The lag correlation has a sharper peak than in the previous figures, the cycle appears to proceed more quickly in the model. Figure 5d shows that often the third mode is related to the AO index of the period in similar fashion to the CCM3 behavior.

Figure 6 shows the plots for the fourteen 20 year segments of the 300 year integration of the ECHAM model. In Fig. 6a the variability from segment to segment is substantially reduced in the Tropics from that shown by the PCM, even in the second mode there is a consistency exceeding that of the CCM3 AMIP ensembles. Evidently, the introduction of an interactive ocean does not guarantee the degree of variation seen in Figs. 5a and b. The percent variance explained, Table 3, on the other hand show a substantial variation, more so than the PCM. The second and third modes tend to be a bit more separated. The lag correlation with Nino3.4, Fig. 6c, has 10 segments with 3 months and 4 of 2 months. This is a tendency to longer lags compared to the PCM but keeping in the 2-3 month range. The lag curve is also a bit broader for the ECHAM as compared to Fig. 5c.The second EOF appears to have some AO component in all the time segments.

\section{b. EOF related spatial patterns}

In this section plots of the projection of the leading EOFs upon the two dimensional time series are presented. The time series are normalized so the patterns indicate the response to a standard deviation change in the EOF.

Figure 7 presents the patterns for the leading two modes of the observations. Figure $7 \mathrm{a}$, the leading mode, clearly depicts the familiar dumbbell shaped pattern in the eastern Equatorial Pacific, first described by YW and Newell and Wu (1992). This pattern is related to the response of the MSU2 to the ENSO events. There is also a pattern like the ubiquitous PNA arching across the northern Pacific and North America. There is a symmetry about the Equator from Pole to Pole with positive values on either side of the Equator becoming sharply negative at higher latitudes. This symmetry is most evident in the Pacific basin.

The regression of the second mode is essentially restricted to poleward of $30 \mathrm{~N}$, 
with extrema tending to be over the continents. Regressions of the $\mathrm{AO}$ index with 1000 hpa geopotential tend to have extrema over the oceans, while similar regression with 1000 to $500 \mathrm{hPa}$ thickness more closely resemble Fig. 7b, Thompson and Wallace (2000). Thompson and Wallace (2000) relate this pattern to the advection by the annular flow of zonal asymmetries generated by land sea temperature contrasts.

Figure 8 is the same as 7, except for the CCM3 AMIP II data. While the patterns of Figs. $8 \mathrm{a}$ and $7 \mathrm{a}$ are quite similar, the model tends to have less amplitude, a notable exception being the minimum over the southern US. All the ensemble members exhibit this behavior. The model has negative values across the eastern North Atlantic and into Europe, while the observations are of comparable magnitude but opposite in sign. This region is a minimum in all but one of the ensemble members. Figures $7 \mathrm{~b}$ and $8 \mathrm{~b}$ are similar. The model has more amplitude over the polar regions and less over the midlatitudes. The model has a minimum in the north Pacific at about the Dateline. This feature is seen in half of the ensemble members and is not evident in the thickness regression of Thompson and Wallace(2000).

The PCM data is shown in two figures, Figs. 9 and10. Figure 9 is for the segment of the PCM having the largest variance explained by the leading mode, while Fig. 10 is the PCM segment having the lowest. In both Figs. 9a and 10a the equatorial east Pacific dumbbell pattern is at best rather ill defined, and is almost absent in Fig.10a. The amplitude of the local tropical signal is quite reduced from the observations. The patterns in the midlatitudes are generally similar to the observations, but both sections have the negative values over the east north Atlantic and Europe seen in the CCM3. In Figs $9 \mathrm{~b}$ and10b, there is an indication of an isolated minima along the Dateline in the north Pacific. The second mode regressions are perhaps more similar to the CCM3 than to the observations. The isolated extrema at the Dateline near $50 \mathrm{~N}$ is a consistent feature of the CCM3 and PCM.

The analogous figures for the ECHAM are shown in Figs. 11 and 12. The equatorial Pacific pattern is again too weak, but it is a bit more distinct and like the observations than the PCM. There is definite evidence for a dumb bell like pattern of reduced amplitude from the observations. The pattern over North America is somewhat zonal compared to observations. The second mode regressions are quite similar in patterns and magnitude to the observations. Figure $11 \mathrm{~b}$ is a good match for $7 \mathrm{~b}$.

Both PCM and ECHAM over all the segments are generally similar, mostly varying with respect to the amplitude of the features. The dumbbell pattern in both inte- 
grations never approaches the distinctness seen in the observations. This is true even for the PCM which has Nino events as strong as observed.

\section{c. Covariance of Precipitation and MSU-2 in the Tropics}

The lack of a distinct ENSO signature in producing the global warming associated with ENSO, would lead to investigating the nature of the precipitation SST link in the models and observations since this is a prominent energy conduit from the ocean to the atmosphere.

Figure 13 is the heterogeneous covariance patterns of the SVD analysis of XA observed precipitation and MSU-2 from $30 \mathrm{~S}$ to $30 \mathrm{~N}$ around the globe. The MSU-2 pattern, Fig. 13a, shows the familiar dumb bell in the eastern Pacific and the rainfall, Fig. 13b, the familiar ENSO related pattern of a maximum anomaly in the equatorial mid Pacific. Both are quite similar to YW. The SCF is 0.81 for this analysis. Figure 14 (a) shows the lag correlations of the expansion coefficients of the MSU and precipitation with each other and each with the Nino 34 index. The precipitation leads the MSU-2 by about a month. The rainfall lags the Nino34 by a month. The MSU lags the Nino34 by about 3 months, although the peak is fairly flat. This three month lag is that identified by $\mathrm{YW}$, as the lag between the MSU-2 residual temperature and the tropical SST. This outlines a sequence of the ocean SST affecting the rainfall initially then later reflected in the tropical mean layer atmospheric temperature.

The patterns of the CCM3 AMIP run, Fig. 15, are consistent with the previous findings. The MSU2 pattern, Fig, 15a, is quite similar to the observed but at a reduced amplitude. The rain pattern, Fig. 15b, has a maximum close to the observed at the Equator about the Dateline. The CCM3 field is more equatorially confined and a bit westward. Perhaps the largest difference is the positive values near the Equator from $60 \mathrm{E}$ to $120 \mathrm{E}$, where the observed data had negative values. Even though the maxima are nearly equal, the observations have a larger area. For example, the $1 \mathrm{~mm} /$ day contour extends over a somewhat larger area in the observations which corresponds to a significant amount of energy. This might account for the somewhat larger MSU response in the observations. These relations and patterns are essentially preserved throughout all the ensemble members.

Figure 16 is the same as 14 except for the PCM sections having the highest and lowest variance explained by the leading EOF. The lag of the MSU expansion coefficient and the Nino3.4 is reduced by a month but the other two relations are the same 
as the observed. The lag correlations are also a bit steeper in the PCM data, this is especially true for the MSU-2 Nino34 curves, which are quite broad in Fig. 14. The SCF is 0.72 for the highest but somewhat reduced to 0.50 in the lowest.

Figures 17 and 18 show the heterogeneous SVD patterns for the PCM data. The MSU patterns are somewhat weaker than the observed and the dumbbell is ill defined, and virtually absent in Fig. 18 which are the figures for the PCM segment showing the smallest variance explained for the leading EOF mode. In a general sense the rainfall patterns are similar to the observed but the maxima along the Equatorial Pacific are pushed westward across the Dateline. The minimum which is seen at about 90W, 20-10S off the coast of Peru in the observations and CCM3, extends equatorward and westward in the PCM. The is a manifestation the model's tendency to produce a tongue of anomalously cold water along the Equator in the eastern Pacific. Although the rainfall is shifted noticeable to the west the MSU response pattern, such as it is, does not appear to be shifted accordingly. The rain shift might just alter the magnitude of the response but not the location.

Figure 19 shows the lag correlation curves for the ECHAM SVD. These show a marked change in character from the previous figures. The MSU2 and precipitation now have a zero lag maximum in correlation of the expansion coefficients, and the curves show a very rapid drop-off compared to the observations, the, CCM3 and PCM and reduced values for the correlation. The phasing of the Nino3.4 and precipitation and MSU-2 time series show the same lag relations as the PCM. The SCF is 0.88 for the highest PVE and drops to 0.65 for lowest.

\section{Discussion and Conclusions}

The addition of 6 years of data to the observational set does very little to alter the results of YW. This is a substantial percentage increase to the data used by YW and does provides some confidence in the robustness of their conclusions. The most consistent aspect of the models is that they are too weak and too fast in altering the MSU-2 temperature in response of Tropical SST anomalies. The weak aspect might not be too surprising in that the SST anomalies produced by the model are generally smaller than that observed over the last 50 years. The too fast aspect is the more troubling feature. One might argue that the models produce an tropical SST anomaly that is too small, but by judicious scaling the processes occurring in the actual atmosphere 
might be recovered. However, the fact that the MSU-2 variations can be three months too fast seriously undermines the scheme. The speed of the model warming confines the phenomena to a single season, and changes the nature of the ENSO interaction with the seasonal cycle. The SVD analysis of the precipitation and MSU-2 temperatures in the Tropics indicates that the dynamic response, as termed by YW, is only slightly fast, if at all. Thus, the speed of the response is due to the thermodynamic processes. The focus of model error traditionally focuses on the error on the rather uncertain convective schemes. In this case, the rather mundane transfer of heat out of the boundary layer and subsequent mixing is the culprit. YW demonstrate that a rather simple model can describe the thermodynamic processes but capturing the essence of the simple model is evidently difficult for the highly complex GCMs.

Another notable fact is the difference in variability amongst the 20 year segments, between the PCM and the ECHAM for the leading EOF of the zonally averaged MSU-2, Figs. 5a and 6a. The ECHAM has somewhat less variation than even the 10 realizations of the CCM3, each of which used the identical SST forcing. It is impossible to verify which model is correct. But unless the CCM3 is an extraordinarily active model the results of the CCM3 ensemble would indicate that the ECHAM model is underestimating the inter-segment variability.

\section{a. Conclusions:}

Based on the EOF analysis of the zonally averaged monthly mean MSU-2 temperature anomalies it is found:

(1) the leading mode is linked to the ENSO cycle in both the observations and GCM simulations.

(2) The phasing of the tropical SSTs and MSU-2 response is different in the simulations and observations. The models both coupled and driven by prescribed SSTs have a lag which is about 2 to 3 months less than the observations.

(3) The second mode is linked to the $\mathrm{AO}$ in the observations, and for the most part this is true for the simulations. In some model simulations cases. the second mode is not related to the AO. In general, this second mode tend to have less separation in the model data than seen in the small observed sample.

An SVD analysis of the tropical, $20 \mathrm{~N}-20 \mathrm{~S}$, covariance of the precipitation and MSU-2 temperatures showed:

(1) The observational leading mode is ENSO related with a distinct precipitation 
anomaly in the equatorial mid Pacific and a dumbbell shaped pattern in the MSU2 straddling the equator in the eastern Pacific. The MSU-2 pattern is the same as the global EOF result. this is as in YW.

(2) the precipitation anomalies for the models are close in magnitude to the observed, although slightly farther west. The MSU-2 response is weak and ill defined in the coupled models.

Overall the models did a fair job in emulating the general interannual variations in the MSU-2 temperatures. There are serious doubts about the models ability to accurately depict the phase relation between the tropical Pacific ENSO SST anomalies and the global tropospheric temperature.

Acknowledgments. The Xie-Arkin precipitation data were obtained from Climate Diagnostics Center. Drs. Warren Washington and Jerry Meehl of NCAR made the PCM data available. Dr. E. Roeckner at MPI provided the ECHAM data. Dr. Maurice Blackmon at NCAR facilitated our obtaining the CSM data. Dr. Michael Wehner of LLNL carried out the ensemble integrations of the NCAR CCM3. This work was performed under the auspices of the U. S. Department of Energy by University of California Lawrence Livermore National Laboratory under contract W-7405-ENG-48. 


\section{References}

Barnston, A. G., M. Cheliah, and S. B. Goldenberg, 1997: Documentation of a highly ENSO-related SST region in the equatorial Pacific. Atmosphere-Ocean, 35, 367383.

Boer, G. J., 1989: Concerning the response of the atmosphere to a tropical sea surface temperature anomaly., J. Atm. Sci., 46, 1898-1921.

Hurrel, J. W., and K. E. Trenberth, 1992: An evaluation of monthly mean MSU and ECMWF global atmospheric temperatures for monitoring climate. J. Climate, $\mathbf{5}$, 1424-1440.

Hurrel, J. W., and K. E. Trenberth, 1997: Spurious trends in satellite MSU temperatures from merging different satellite records. Nature, 386, 164-167.

Hurrel, J. W., and K. E. Trenberth, 1999: difficulties in obtaining reliable temperature trends: reconciling the surface and satellite MSU record. J. Climate, 11, 945-967.

Kidson, J. W., 1988: Interannual variations in the Southern Hemisphere circulation. J. Climate, 1, 1177-1198.

Kiehl, J. T., J. J. Hack, G. Bonan, B. Boville, D. Williamson, and P. Rasch, 1998: The National Center for Atmospheric Research Community Climate Model(CCM3). J. Climate, 11, 1131-1149.

Newell, R. E., and Z.-X. Wu, 1992: The interrelationship between temperature changes in the free atmosphere and sea-surface temperature changes. J. Geophys. Res., 97D, 3693-3907.

Roeckner, E., L. Bengtsson, J. Feichter, J. Lelieveld, and H. Rodie, 1999: Transient climate change simulations with a coupled atmosphere-ocean GCM including the tropospheric sulfur cycle. J. Climate, 12, 3004-3032.

Spencer, R. W., and J. R. Christy, 1992: Precision and radiosonde validation of satellite gridpoint temperature anomalies, Part I: MSU channel 2. J. Climate, 5, 847857.

Spencer, R. W., J. R. Christy, and N. C. Grody, 1990: Global atmospheric temperature monitoring with satellite microwave measurements: Method and results 197984. J. Climate, 3, 1111-1128.

Thompson, D. W. J., and J. M. Wallace, 2000: Annular modes in the extratropical circulation: Part I: Month to month variability. J. Clim., 13, 1000-1016. 
Thompson, D. W. J., and J. M. Wallace, 1998: The arctic oscillation signature in the wintertime geopotential height and temperature fields. Geophys. Res. Lett., 25, 1297-1300.

Washington, W. M., and Coauthors, 2000: Parallel Climate Model (PCM) control and $1 \%$ per year $\mathrm{CO} 2$ simulations with a $2 / 3$ degree ocean model and a $27-\mathrm{km}$ dynamical sea ice model. Climate Dyn., in press

Xie, P., and P, A. Arkin, 1997: Global precipitation: A 17 year monthly analysis based on gauge observations, satellite estimates and numerical model outputs. Bull. Am. Met. Soc., 78, 2539-2558.

Yulaeva, E., and J. M. Wallace, 1994: The signature of ENSO in global temperature and precipitation fields derived from the microwave sounding unit. J. Climate., 7, 1719-1736. 


\section{List of Tables}

Table 1. Percent variance explained by the leading 4 EOFs of the zonally averaged monthly mean MSU2 anomalies for the observations and 10 realizations of the CCM3. The observations are for the period 1979-1996. The CCM3 integrations use prescribed SSTs for the period 1979 through 1995.

Table 2. Percent variance explained by the leading 4 EOFs of the zonally averaged monthly mean MSU2 anomalies for fourteen 20 year segments of the PCM 300 year control integration.

Table 3. Percent variance explained by the leading 4 EOFs of the zonally averaged monthly mean MSU2 anomalies for fourteen 20 year segments of the ECHAM 300 year control integration.

Table 4. The squared covariance fraction explained by the first three modes of the SVD analysis of tropical ( $30 \mathrm{~S}-30 \mathrm{~N}$ ) MSU2 temperatures and precipitation for six data sets. 


\begin{tabular}{|l|l|l|l|l|}
\hline \multicolumn{1}{|c|}{ DataSet } & \multicolumn{1}{|c|}{ EOF 1} & \multicolumn{1}{|c|}{ EOF 2} & \multicolumn{1}{c|}{ EOF 3} & \multicolumn{1}{c|}{ EOF 4} \\
\hline \hline MSU-2 & 44 & 13 & 9 & 8 \\
\hline CCM3-AMIP & 41 & 17 & 11 & 8 \\
\hline CCM3 - 1 & 43 & 15 & 12 & 8 \\
\hline CCM3 - 2 & 43 & 14 & 11 & 9 \\
\hline CCM3 - 3 & 40 & 16 & 12 & 9 \\
\hline CCM3 - 4 & 43 & 15 & 11 & 8 \\
\hline CCM3 - 5 & 46 & 13 & 10 & 8 \\
\hline CCM3 - 6 & 46 & 13 & 11 & 7 \\
\hline CCM3 - 7 & 43 & 14 & 10 & 9 \\
\hline CCM3 - 8 & 43 & 14 & 10 & 9 \\
\hline CCM3 - 9 & 40 & 15 & 13 & 9 \\
\hline
\end{tabular}

Table 1. Percent variance explained by the leading 4 EOFs of the zonally averaged monthly mean MSU2 anomalies for the observations and 10 realizations of the CCM3. The observations are for the period 1979-1996. The CCM3 integrations use prescribed SSTs for the period 1979 through 1995. 


\begin{tabular}{|c|c|c|c|c|}
\hline $\begin{array}{c}\text { PCM time } \\
\text { section }\end{array}$ & EOF 1 & EOF 2 & EOF 3 & EOF4 \\
\hline \hline $20--40$ & 37 & 17 & 13 & 10 \\
\hline $40-60$ & 36 & 15 & 14 & 10 \\
\hline $60-80$ & 42 & 14 & 12 & 8 \\
\hline $80-100$ & 30 & 19 & 15 & 10 \\
\hline $100-120$ & 41 & 16 & 13 & 9 \\
\hline $120-140$ & 33 & 15 & 14 & 12 \\
\hline $140-160$ & 32 & 18 & 14 & 11 \\
\hline $160-180$ & 31 & 16 & 15 & 12 \\
\hline $180-200$ & 40 & 15 & 12 & 11 \\
\hline $200-220$ & 42 & 14 & 13 & 9 \\
\hline $220-240$ & 30 & 18 & 16 & 10 \\
\hline $240-260$ & 32 & 18 & 14 & 9 \\
\hline $260-280$ & 40 & 15 & 13 & 19 \\
\hline $280-300$ & 36 & 15 & 12 & 10 \\
\hline
\end{tabular}

Table 2 . Percent variance explained by the leading 4 EOFs of the zonally averaged monthly mean MSU2 anomalies for fourteen 20 year segments of the PCM 300 year control integration. 


\begin{tabular}{|l|l|l|l|l|}
\hline $\begin{array}{c}\text { ECHAM time } \\
\text { section }\end{array}$ & EOF 1 & EOF 2 & EOF 3 & EOF 4 \\
\hline \hline $20-40$ & 43 & 12 & 9 & 8 \\
\hline $40-60$ & 47 & 12 & 9 & 8 \\
\hline $60-80$ & 49 & 12 & 10 & 7 \\
\hline $80-100$ & 47 & 12 & 10 & 8 \\
\hline $100-120$ & 44 & 12 & 11 & 9 \\
\hline $120-140$ & 47 & 12 & 10 & 8 \\
\hline $140-160$ & 54 & 11 & 9 & 7 \\
\hline $160-180$ & 36 & 14 & 13 & 10 \\
\hline $180-200$ & 44 & 12 & 10 & 9 \\
\hline $200-220$ & 43 & 13 & 11 & 8 \\
\hline $220-240$ & 39 & 13 & 11 & 10 \\
\hline $240-260$ & 36 & 13 & 12 & 10 \\
\hline $260-280$ & 31 & 15 & 13 & 10 \\
\hline $280-300$ & 51 & 11 & 9 & 8 \\
\hline
\end{tabular}

Table 3. Percent variance explained by the leading 4 EOFs of the zonally averaged monthly mean MSU2 anomalies for fourteen 20 year segments of the ECHAM 300 year control integration. 


\begin{tabular}{|l|l|l|l|}
\hline \multicolumn{1}{|c|}{ Dataset } & \multicolumn{1}{c|}{ mode 1 } & \multicolumn{1}{c|}{ mode 2 } & \multicolumn{1}{c|}{ mode3 } \\
\hline \hline Xie-Arkin MSU2 & 0.80 & 0.10 & 0.02 \\
\hline CCM3 AMIP II simulation & 0.81 & 0.038 & 0.018 \\
\hline PCM model years 60 - 80 & 0.72 & 0.05 & 0.05 \\
\hline PCM model years 80-100 & 0.50 & 0.09 & 0.08 \\
\hline ECHAM4 model years 140-160 & 0.88 & 0.031 & 0.018 \\
\hline ECHAM4 model years 260-280 & 0.65 & 0.06 & 0.05 \\
\hline
\end{tabular}

Table 4. The squared covariance fraction explained by the first three modes of the SVD analysis of tropical (30S-30N) MSU2 temperatures and precipitation for six data sets. 


\section{List of Figures}

Figure 1. Histogram of the normalized frequencies of the SST anomalies in the Nino3-4 region for the observed (solid), PCM (dash-dot), and ECHAM (dash) data. The observations are for the period 1950 to 1998 . The model data are for 280 years of simulation.

Figure 2. (a) The leading two EOFs of the covariance matrix of zonally averaged observed MSU-2 monthly mean temperature anomalies for the period 1979 to 1998 . The first EOF is the solid line, the second is the dashed. They account for 44 and 13 percent of the temporal variance.

(b) The lag correlation between the leading EOF of the observed MSU-2 temperatures and the Nino34 time series. The positive lag indicates the Nino34 leads the MSU-2.

(c) The lag correlation between the second EOF of the observed MSU-2 temperature and the Arctic Oscillation Index.

Figure 3. (a) The leading two EOFs of the covariance matrix of zonally averaged CCM3 MSU-2 monthly mean temperature anomalies for the period 1979 to 1998 . The first EOF is the solid line, the second is the dashed.

(b) The lag correlation between the leading EOF of the CCM3 MSU-2 temperatures and the Nino3/4 time series. The positive lag indicates the Nino34 leads the MSU-2.

(c) The lag correlation between the second EOF of the CCM3 MSU-2 temperature and the Arctic Oscillation Index.

Figure 4. (a) The leading EOF of the covariance matrix of zonally averaged monthly mean MSU2 temperature anomalies for ten realizations of the CCM3 for the period 1979 to 1998.

(b) As in (a) except for the second EOF.

(c) The lag correlation between the leading EOF of the ten realizations of the CCM3 MSU-2 temperatures and the Nino3/4 time series. The positive lag indicates the Nino34 leads the MSU-2.

(d) The lag correlation between the second EOF of the ten realizations of the CCM3 MSU-2 temperature and the Arctic Oscillation Index.

Figure 5. (a) The leading EOF of the covariance matrix of zonally averaged monthly mean MSU2 temperature anomalies for fourteen 20 year segments of the PCM.

(b) As in (a) except for the second EOF.

(c) The lag correlation between the leading EOF of the MSU-2 temperatures and the Nino3/4 time series for fourteen 20 year segments of the PCM. The positive lag indicates the Nino34 leads the MSU-2. (d) The lag correlation between the second EOF of the MSU-2 temperature for fourteen 20 year segments of the PCM and the Arctic Oscillation Index. 
Figure 6. (a) The leading EOF of the covariance matrix of zonally averaged monthly mean MSU2 temperature anomalies for fourteen 20 year segments of the ECHAM.

(b) As in (a) except for the second EOF.

(c) The lag correlation between the time series of the leading EOF of the MSU-2 temperatures and the Nino3.4 time series for fourteen 20 year segments of the ECHAM. The positive lag indicates the Nino3.4 leads the MSU-2.

(d) The lag correlation between the second EOF of the MSU-2 temperature for fourteen 20 year segments of the ECHAM and the Arctic Oscillation Index computed for those segments.

Figure 7. (a) The projection of the leading EOF mode of the zonally averaged MSU2 monthly mean anomalies onto the MSU2 monthly mean data. The time series was normalized such that the contours indicate the MSU2 anomaly corresponding to a standard deviation EOF. Contour interval is 0.5 . Solid lines indicate positive values, dashed lines indicate negative values.

(b) As in (a) except for the second EOF. Since this mode only has significant amplitude in the Northern Hemisphere, only this part of the globe is displayed.

Figure 8. (a) As in 7(a) except for the CCM3 AMIP2 simulated MSU2.

(b) As in 7(b) except for the CCM3 AMIP2 simulated MSU2.

Figure 9. (a) As in 7(a) except for the PCM segment with the highest percent variance explained by the leading mode of the fourteen 20 year segments.

(b) As in 7(b) except for the PCM segment with the highest percent variance explained by the leading mode of the fourteen 20 year segments.

Figure 10. (a) As in 7(a) except for the PCM segment with the lowest percent variance explained by the leading mode of the fourteen 20 year segments.

(b) As in 7(b) except for the PCM segment with the lowest percent variance explained by the leading mode of the fourteen 20 year segments.

Figure 11. (a) As in 7(a) except for the ECHAM segment with the highest percent variance explained by the leading mode of the fourteen 20 year segments.

(b) As in 7(b) except for the ECHAM segment with the highest percent variance explained by the leading mode of the fourteen 20 year segments.

Figure 12. (a) As in 7(a) except for the ECHAM segment with the lowest percent variance explained by the leading mode of the fourteen 20 year segments.

(b) As in 7(b) except for the ECHAM segment with the lowest percent variance explained by the leading 
mode of the fourteen 20 year segments.

Figure 13. (a) The heterogeneous pattern of the MSU2 for the SVD analysis of the observed tropical precipitation and for the observed MSU2 data.

(b) As in (a) except for the observed precipitation.

Figure 14. (a) The lag correlation between the time series of expansion coefficients for the MSU2 for the SVD analysis of the observed tropical precipitation and for the observed MSU2 data and the expansion coefficients for the observed precipitation (solid line). The lag correlation between the expansion coefficients of the precipitation and the Nino3.4 time series (dashed line). The lag correlation between the expansion coefficients of the MSU2 and the Nino3.4 time series (dash-dot line).

(b) As in (a) except for the CCM3 AMIP2 data.

Figure 15. (a) As in 13(a) except for the CCM3 AMIP2 data.

(b) As in 13(b) except for the CCM3 AMIP2 data.

Figure 16. (a) As in 13(a) except for the PCM segment having the highest percent variance explained for the leading mode of the EOF of zonally averaged monthly mean MSU2 anomalies.

(b) As in Fig. 13(b) except for the PCM segment having the highest percent variance explained for the leading mode of the EOF of zonally averaged monthly mean MSU2 anomalies.

Figure 17. As in Fig, 14(a) except for the PCM segment having the highest percent variance explained for the leading mode of the EOF of zonally averaged monthly mean MSU2 anomalies.

(b) As in Fig, 14(a) except for the PCM segment having the lowest percent variance explained for the leading mode of the EOF of zonally averaged monthly mean MSU2 anomalies.

Figure 18. (a) As in 13(a) except for the PCM segment having the lowest percent variance explained for the leading mode of the EOF of zonally averaged monthly mean MSU2 anomalies.

(b) As in Fig. 13(b) except for the PCM segment having the lowest percent variance explained for the leading mode of the EOF of zonally averaged monthly mean MSU2 anomalies.

Figure 19. (a) As in 13(a) except for the ECHAM segment having the highest percent variance explained for the leading mode of the EOF of zonally averaged monthly mean MSU2 anomalies.

(b) As in Fig. 13(b) except for the ECHAM segment having the highest percent variance explained for the leading mode of the EOF of zonally averaged monthly mean MSU2 anomalies.

Figure 20. As in Fig, 14(a) except for the ECHAM segment having the highest percent variance explained for the leading mode of the EOF of zonally averaged monthly mean MSU2 anomalies. 
(b) As in Fig, 14(a) except for the ECHAM segment having the lowest percent variance explained for the leading mode of the EOF of zonally averaged monthly mean MSU2 anomalies.

Figure 21. (a) As in 13(a) except for the ECHAM segment having the lowest percent variance explained for the leading mode of the EOF of zonally averaged monthly mean MSU2 anomalies.

(b) As in Fig. 13(b) except for the ECHAM segment having the lowest percent variance explained for the leading mode of the EOF of zonally averaged monthly mean MSU2 anomalies. 


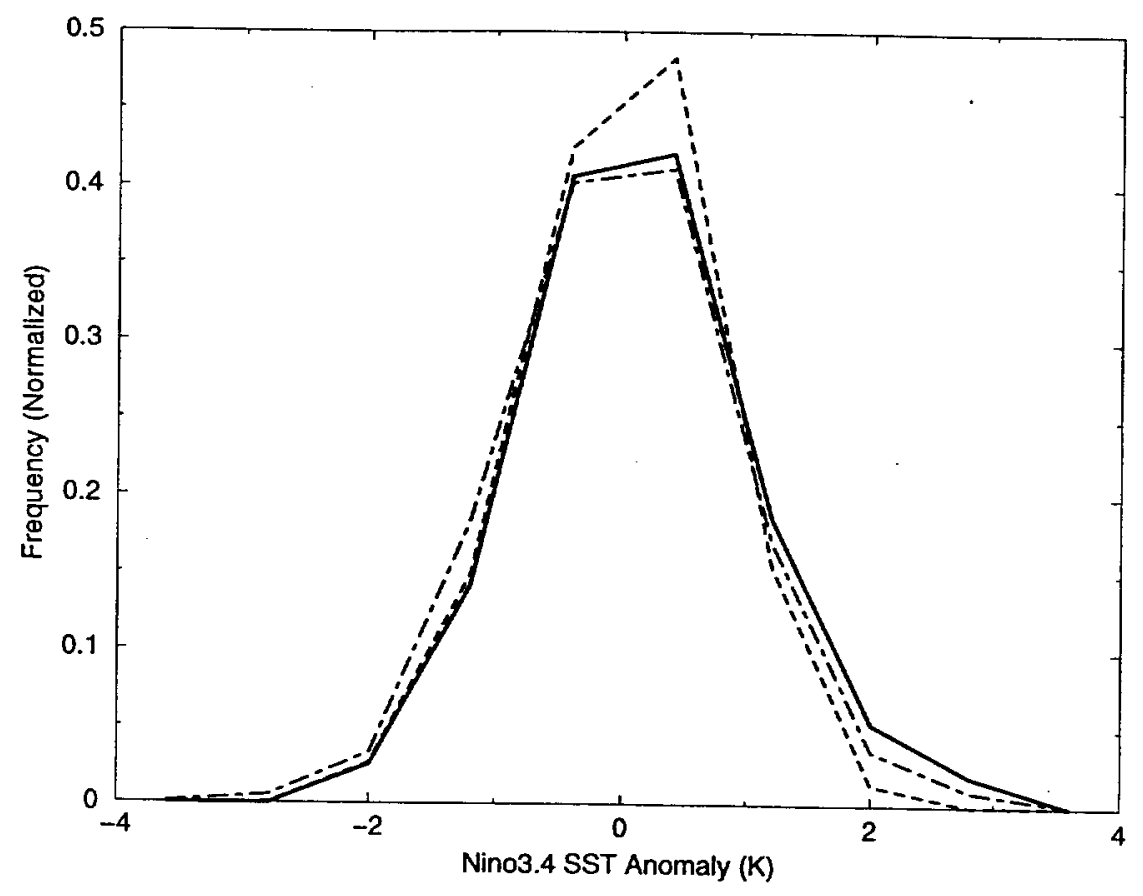

Figure 1. Histogram of the normalized frequencies of the SST anomalies in the Nino3-4 region for the observed (solid) , PCM (dash-dot), and ECHAM (dash) data. The observations are for the period 1950 to 1998 . The model data are for 280 years of simulation. 

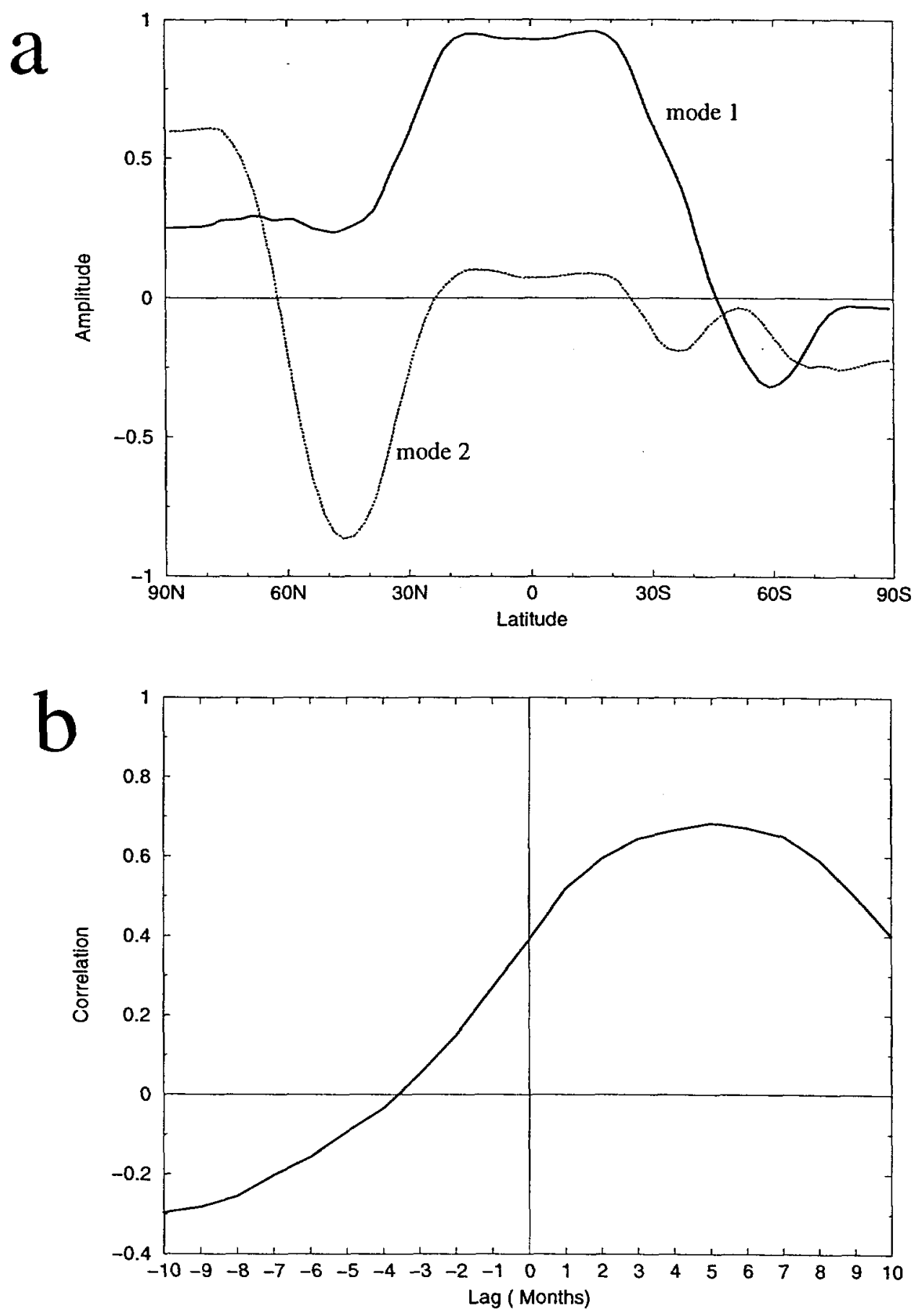

Figure 2. (a) The leading two EOFs of the covariance matrix of zonally averaged observed MSU-2 monthly mean temperature anomalies for the period 1979 to 1998 . The first EOF is the solid line, the second is the dashed. They account for 44 and 13 percent of the temporal variance.

(b) The lag correlation between the leading EOF of the observed MSU-2 temperatures and the Nino34 time series. The positive lag indicates the Nino34 leads the MSU-2. 


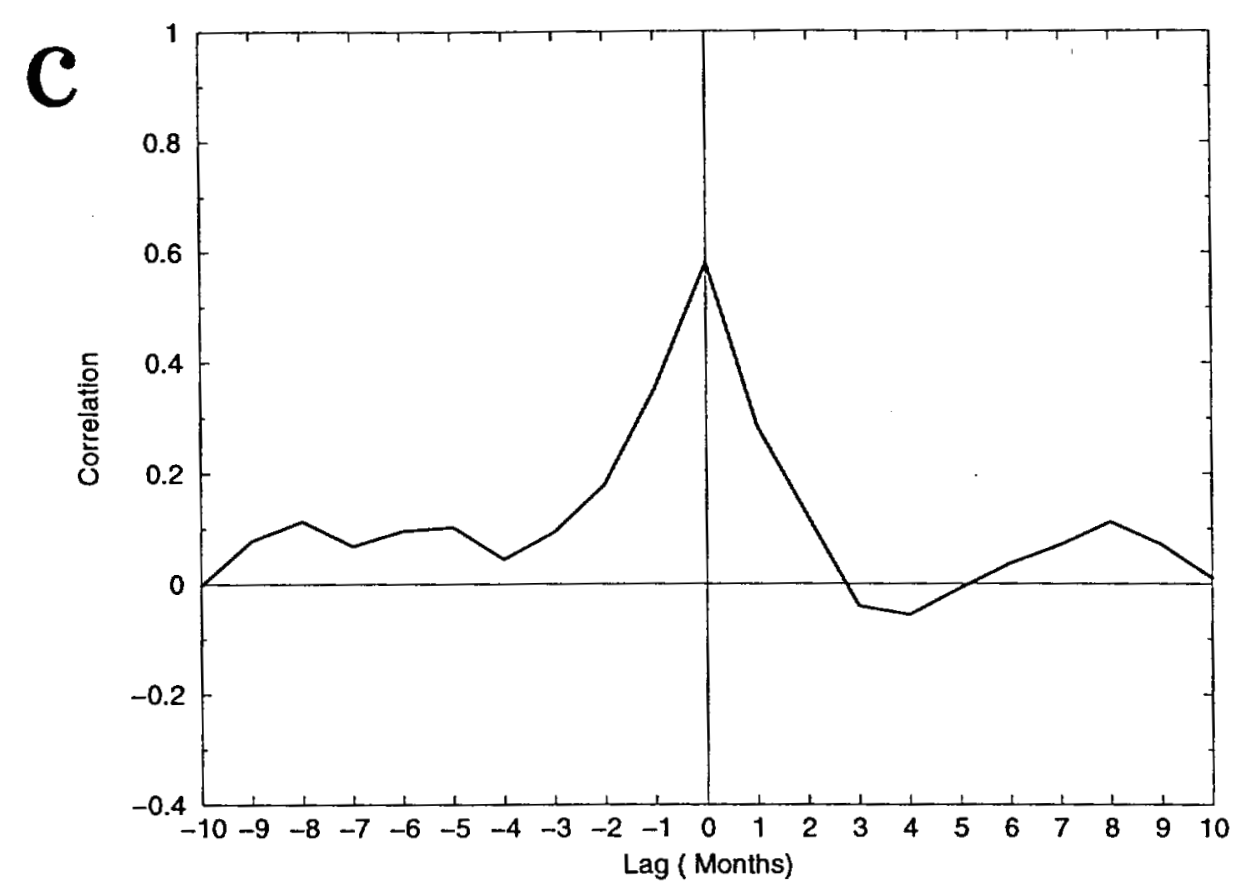

Figure 2 (c) The lag correlation between the second EOF of the observed MSU-2 temperature and the Arctic Oscillation Index 

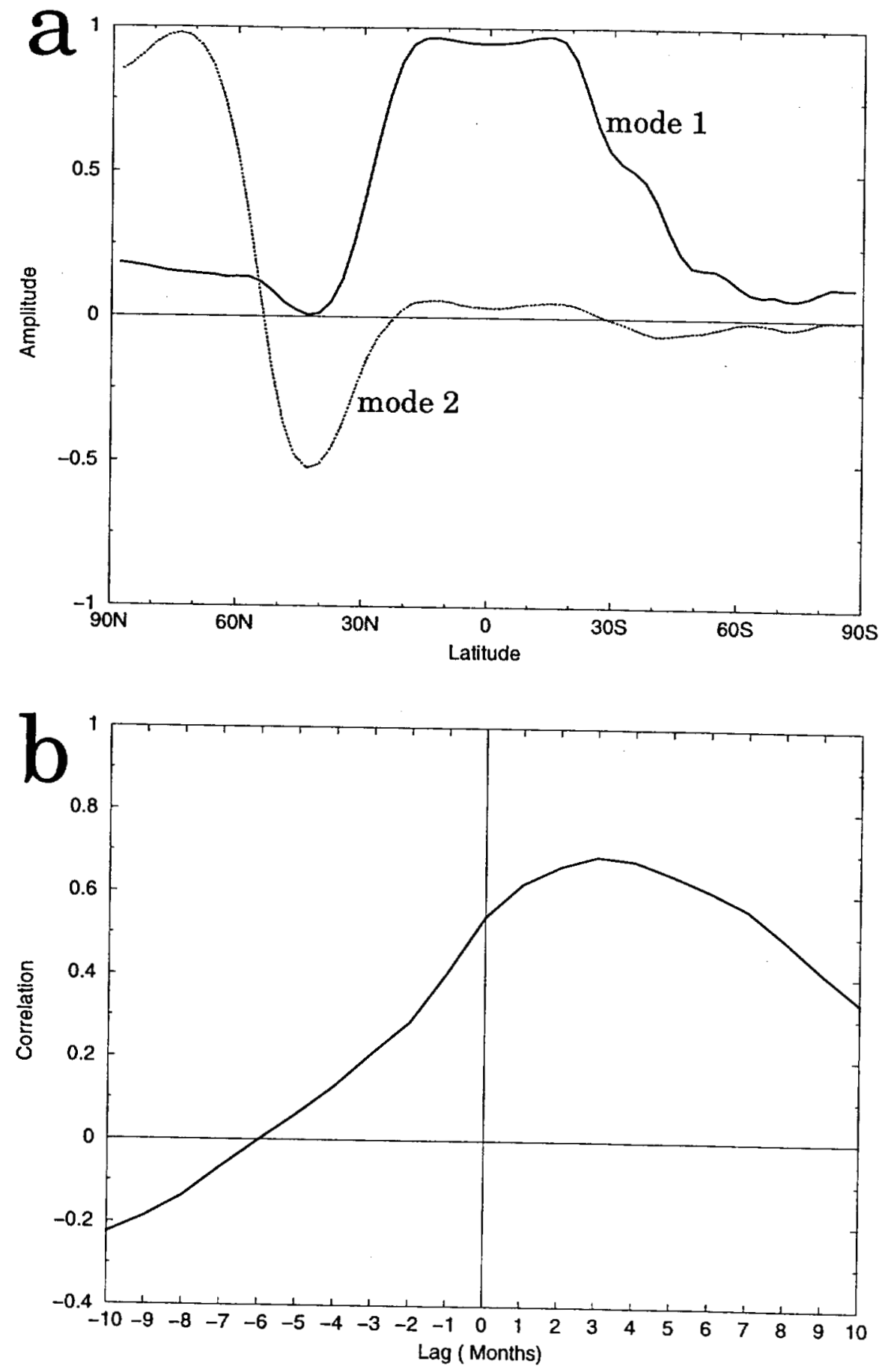

Figure 3. 


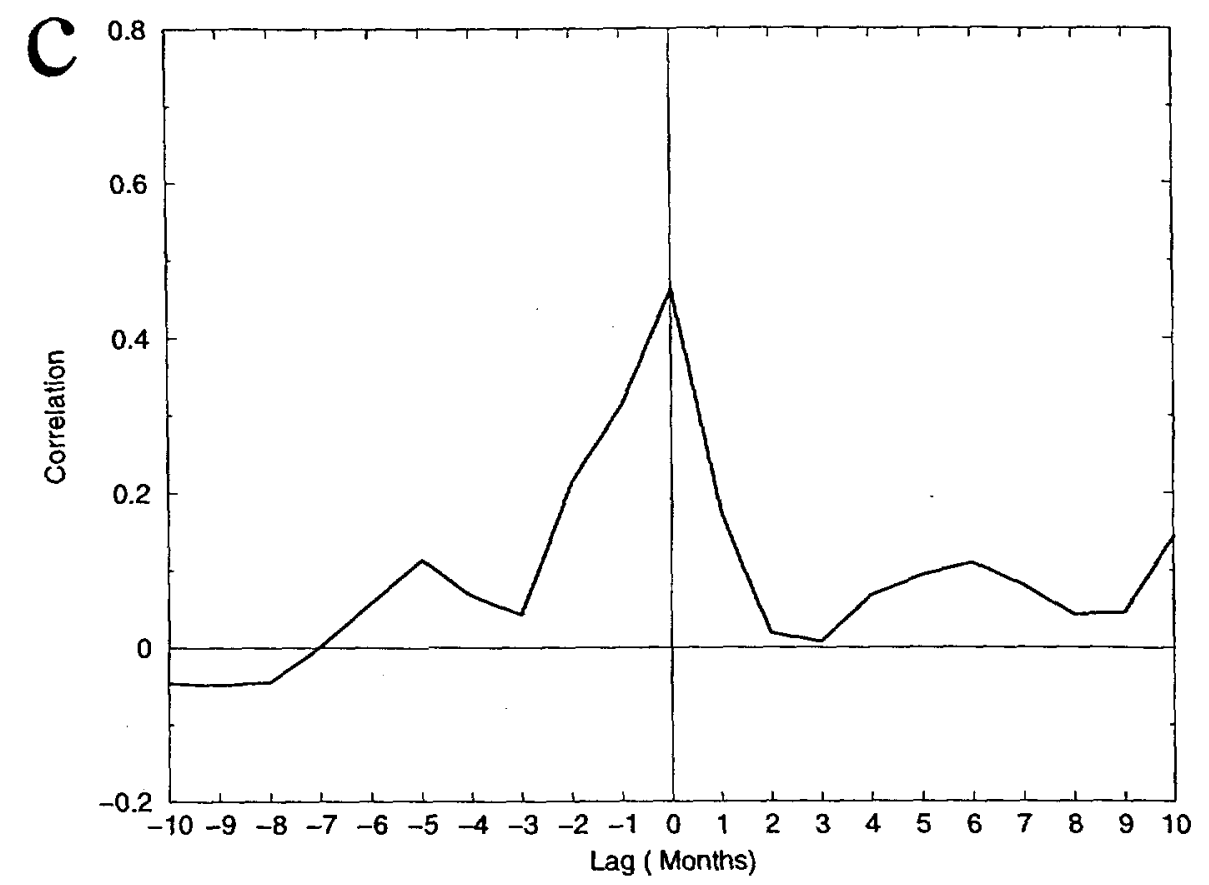

Figure 3 (c) 

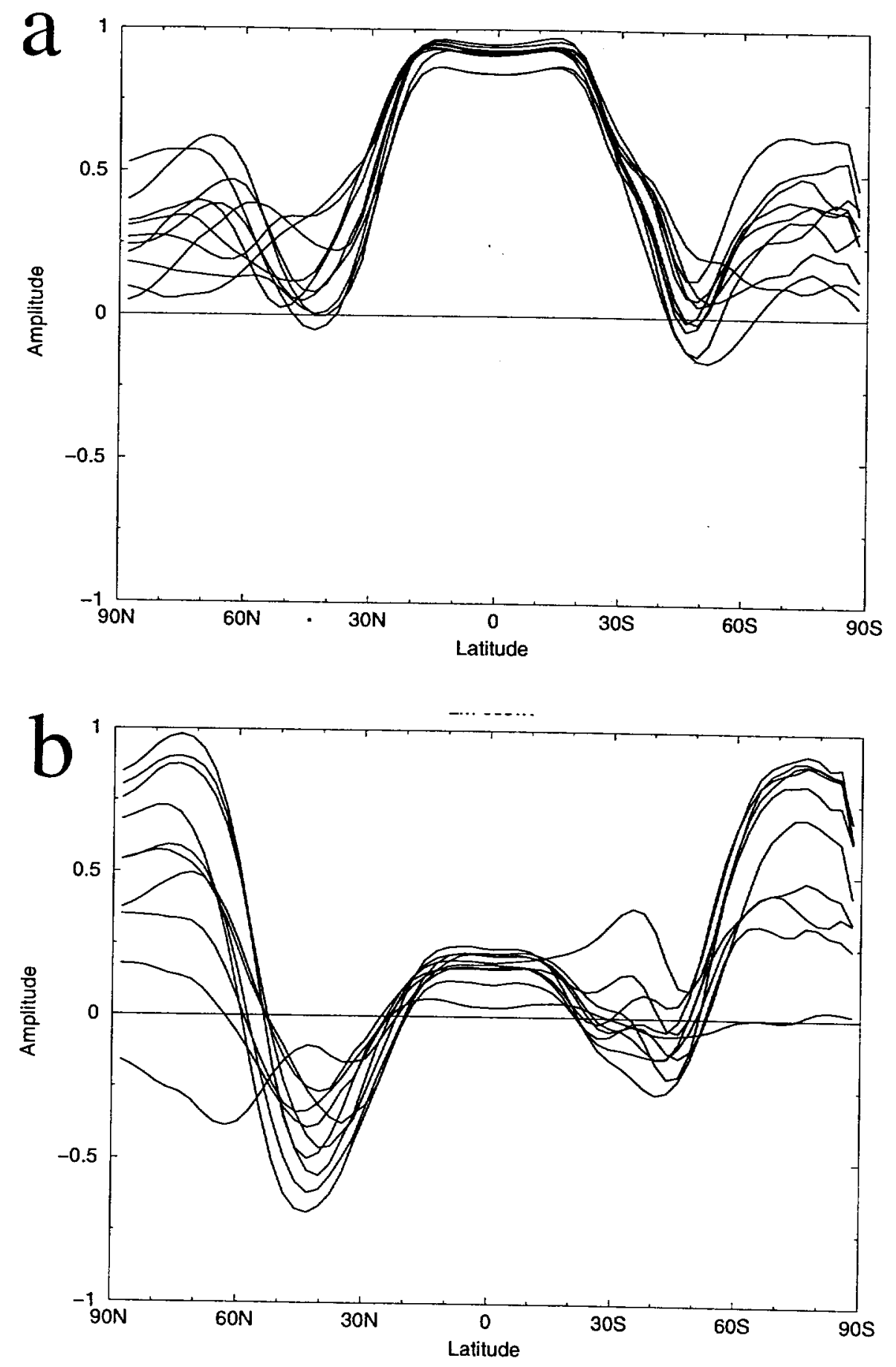

Figure 4 (a), (b) 

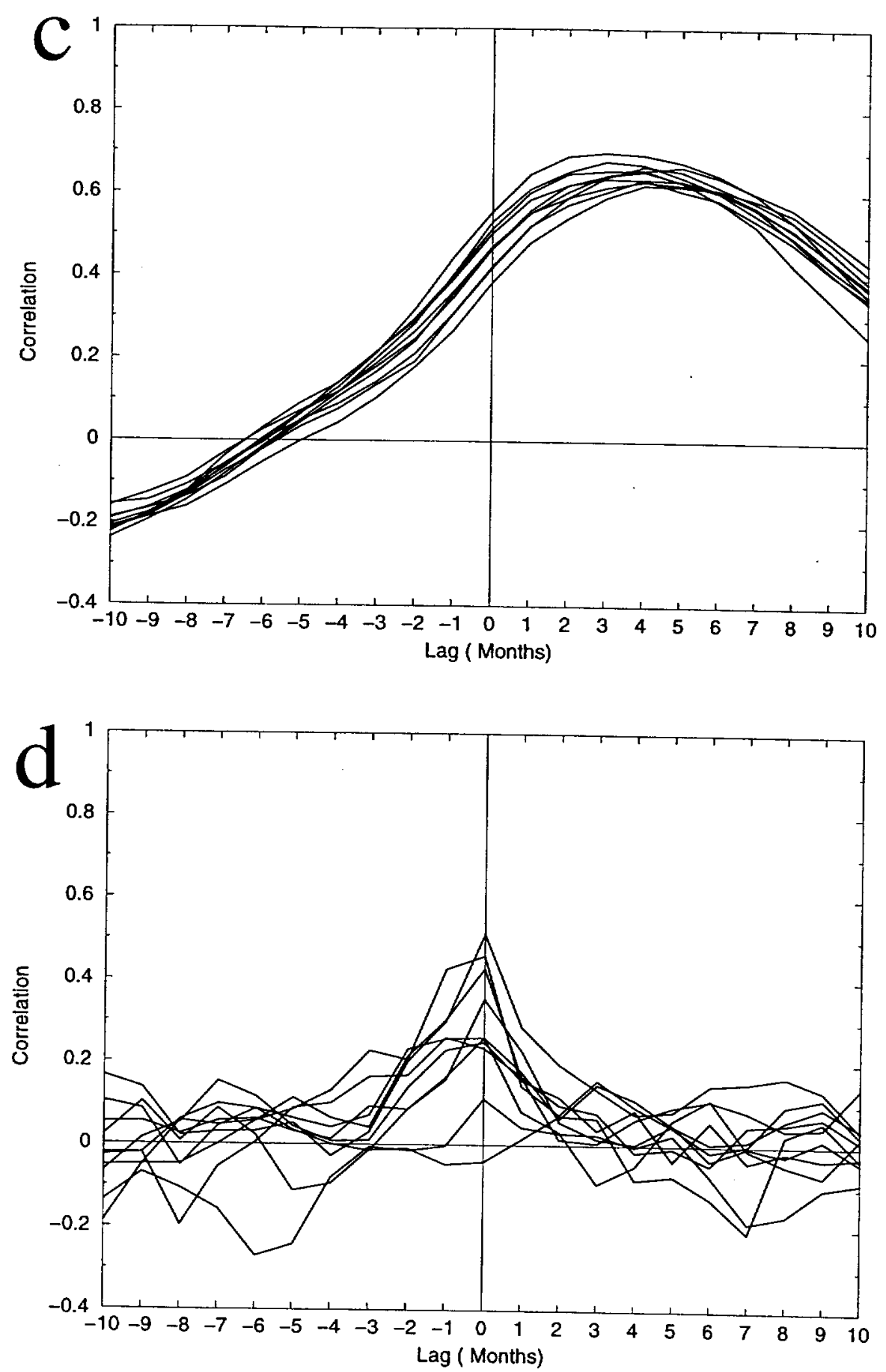

Figure 4 (c), (d) 

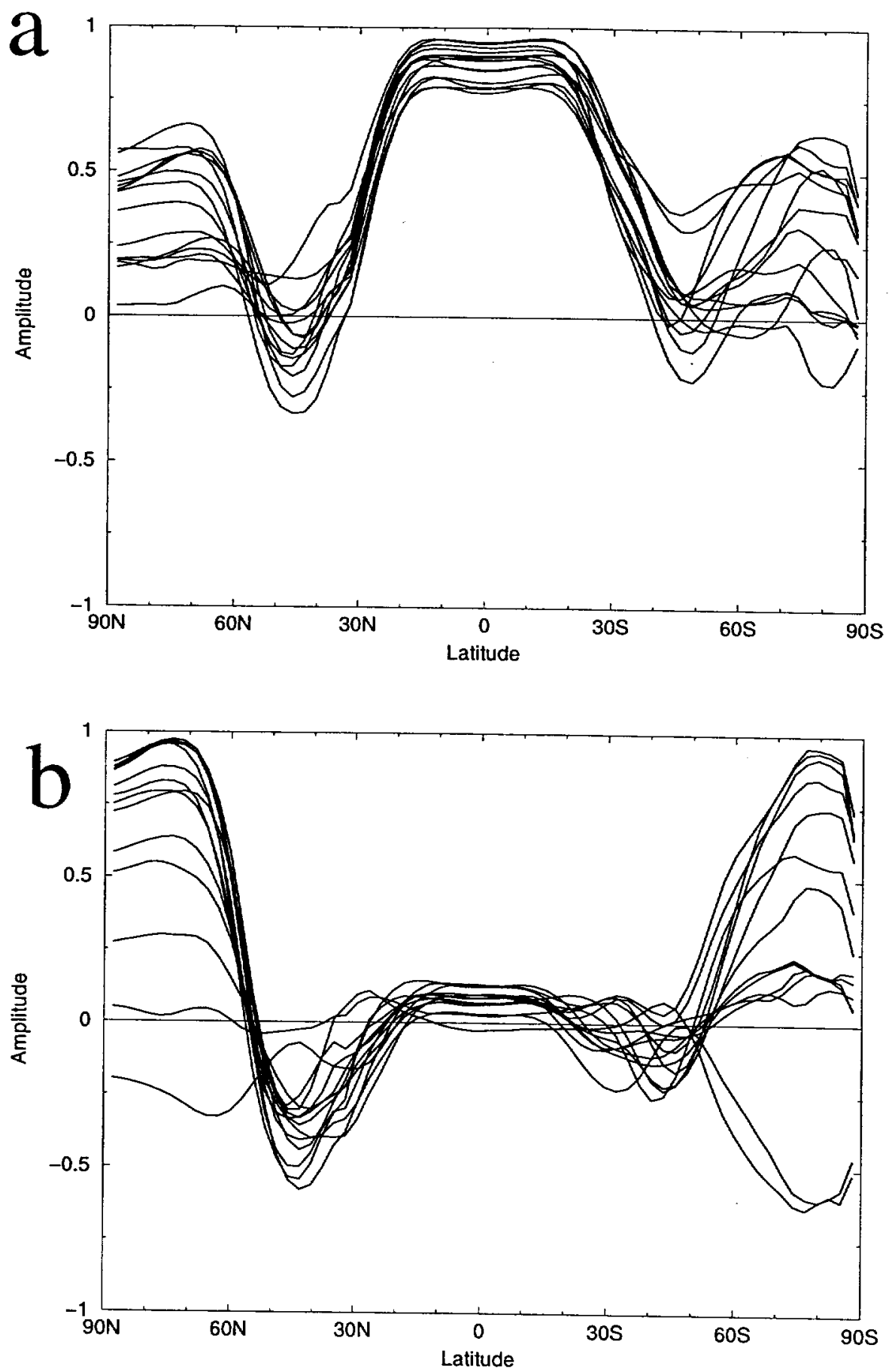

Figure 5 (a), (b) 

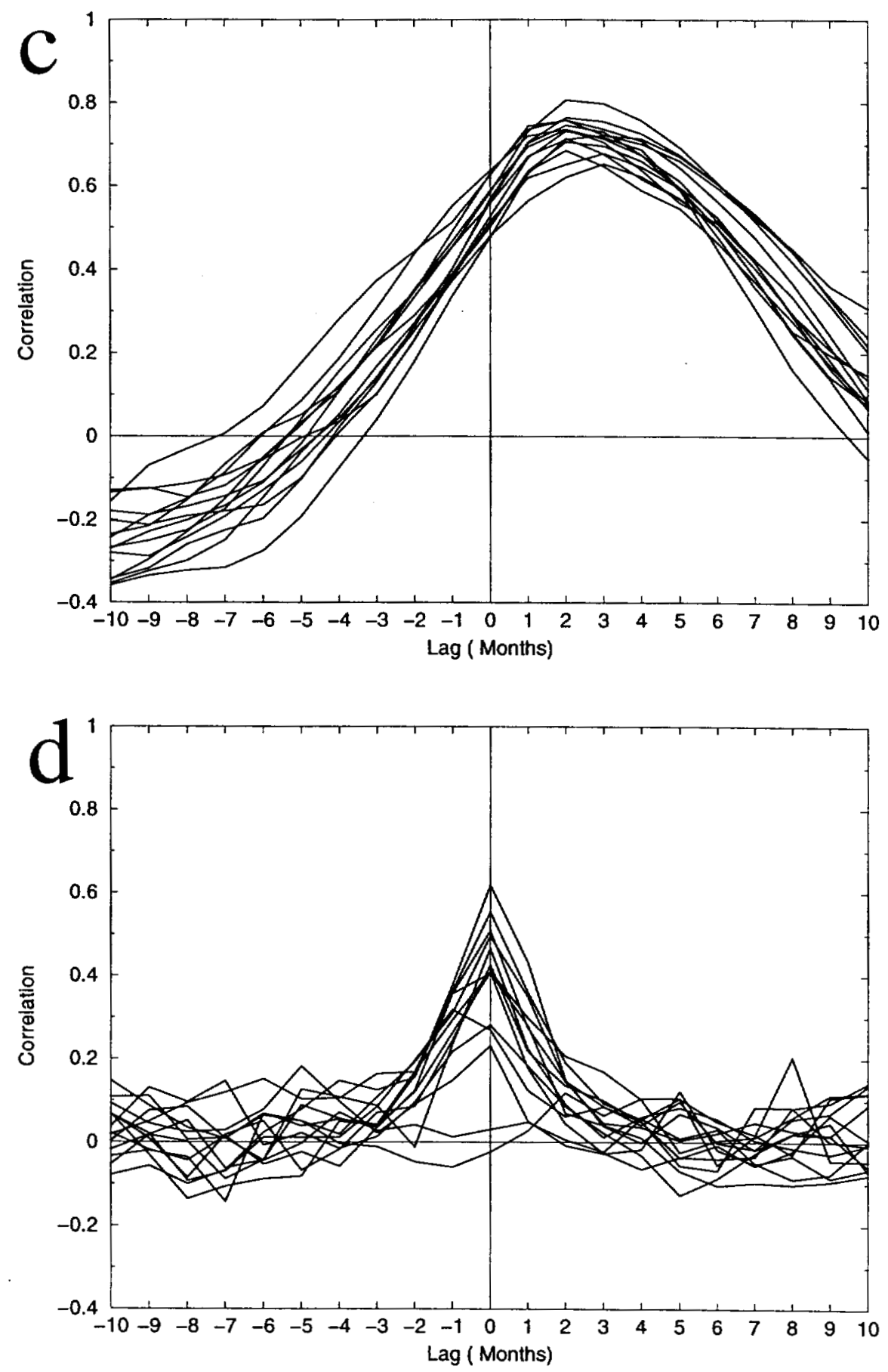

Figure 5 (c), (d) 

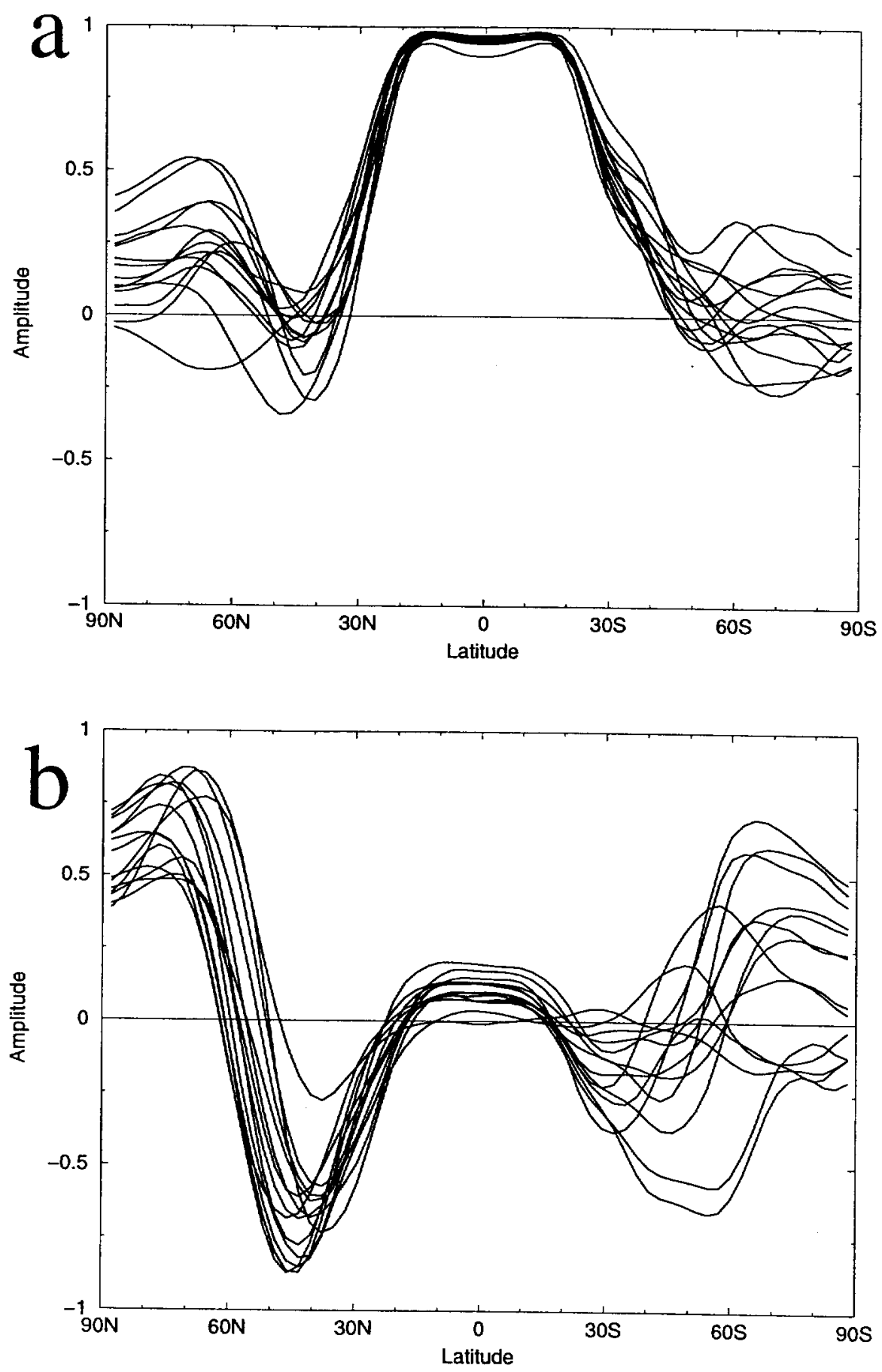

Figure 6 (a), (b) 

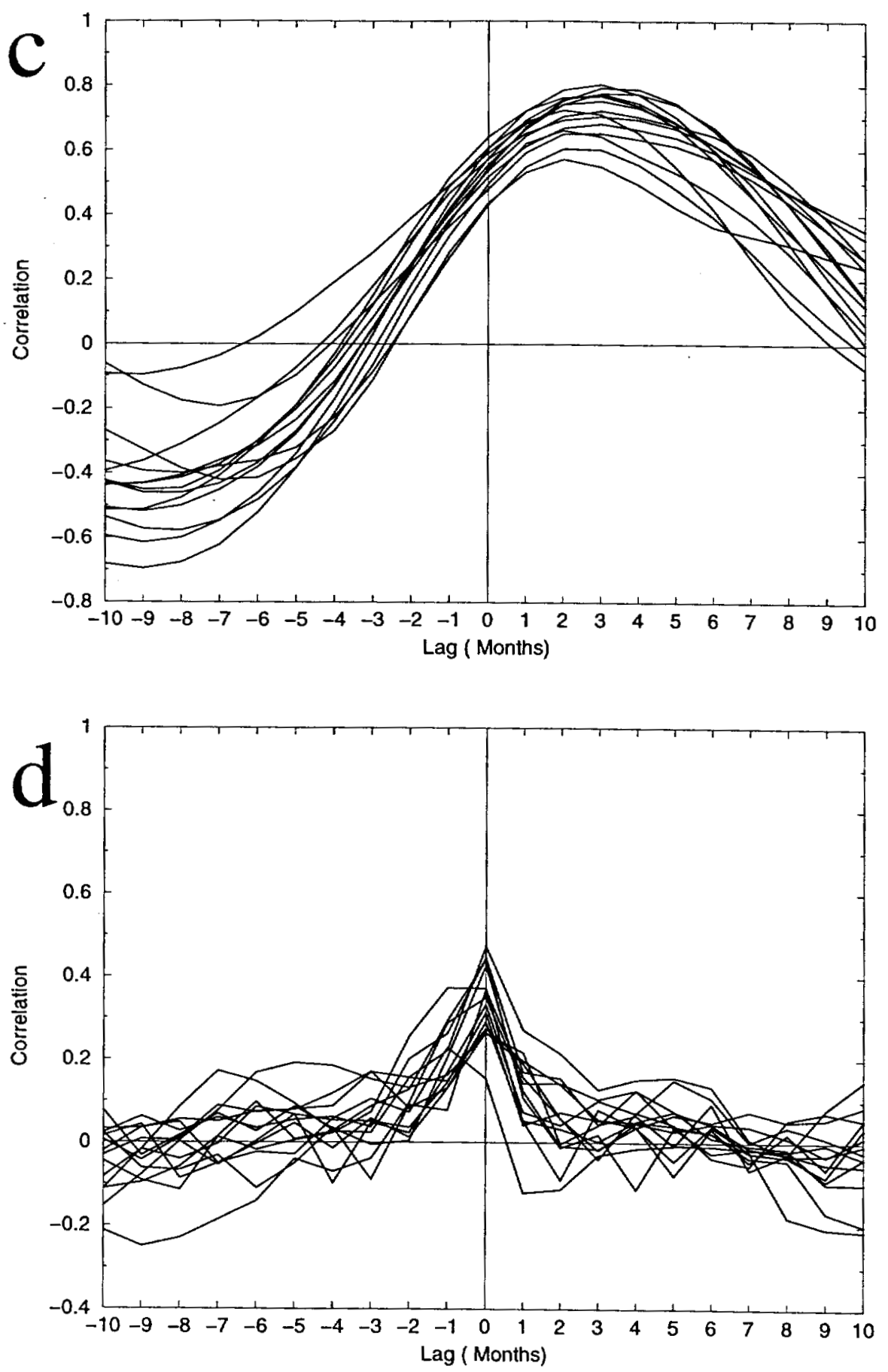

Figure 6 (c), (d) 

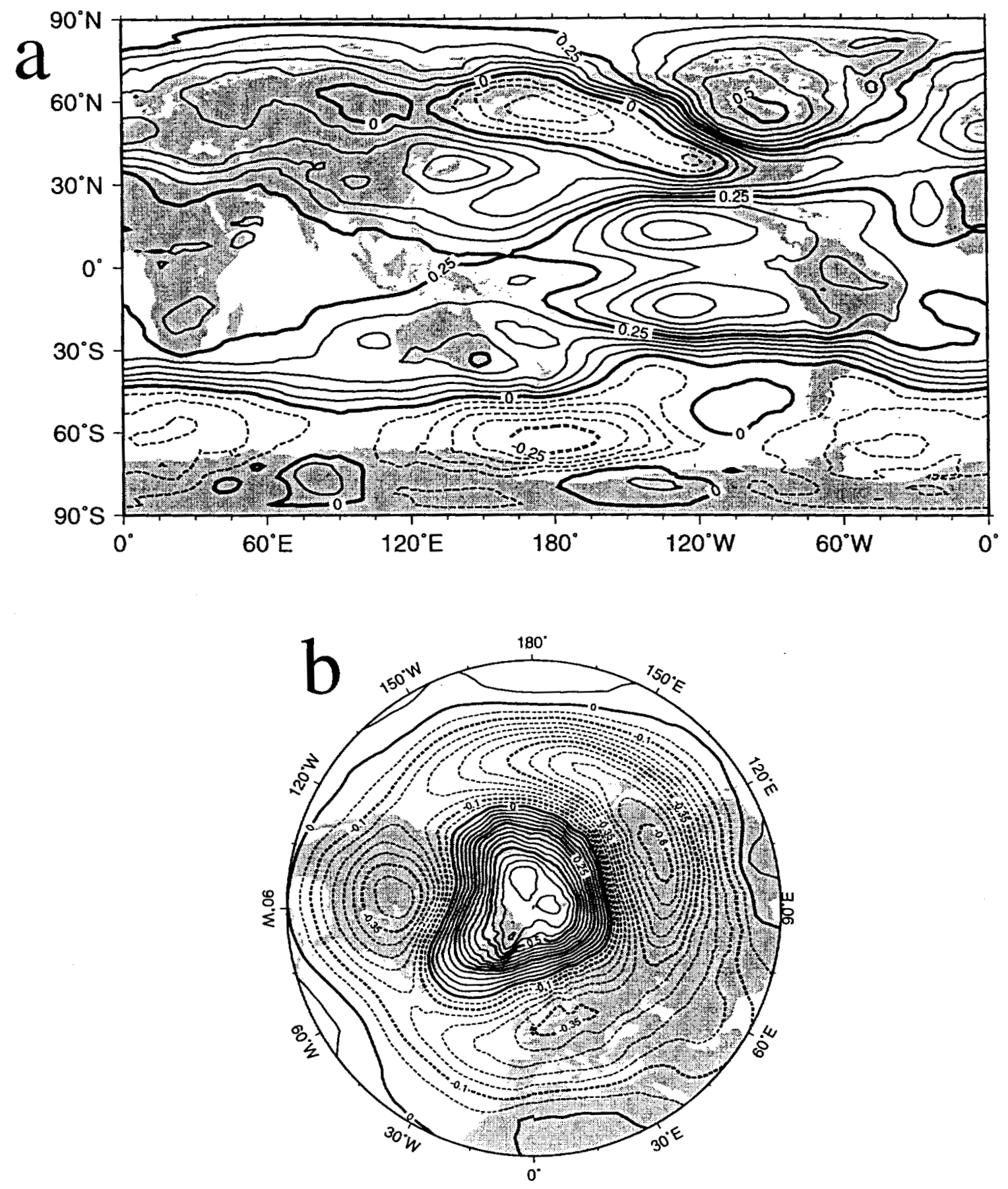

Figure 7 (a), (b) 

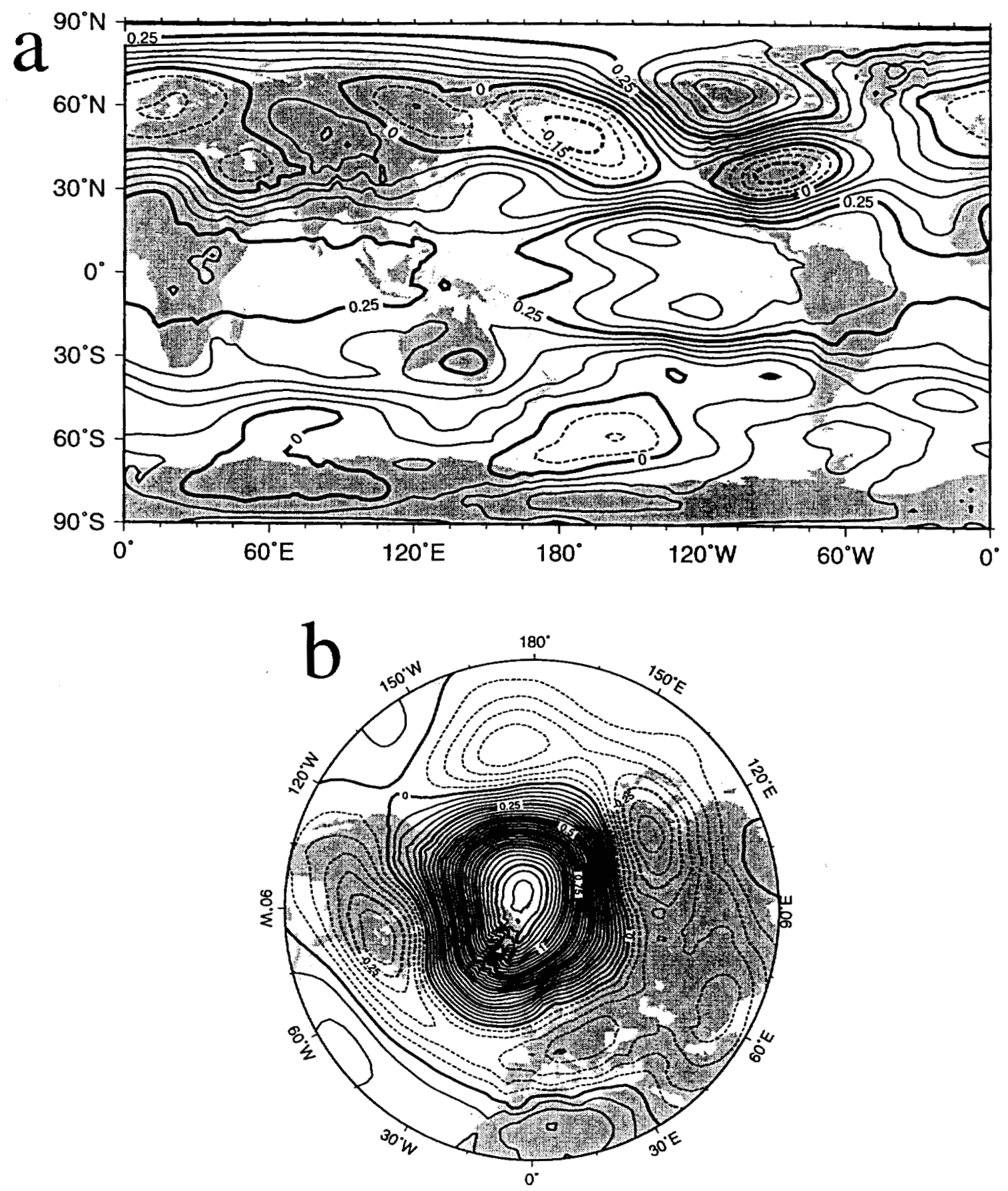

Figure 8 (a), (b) 


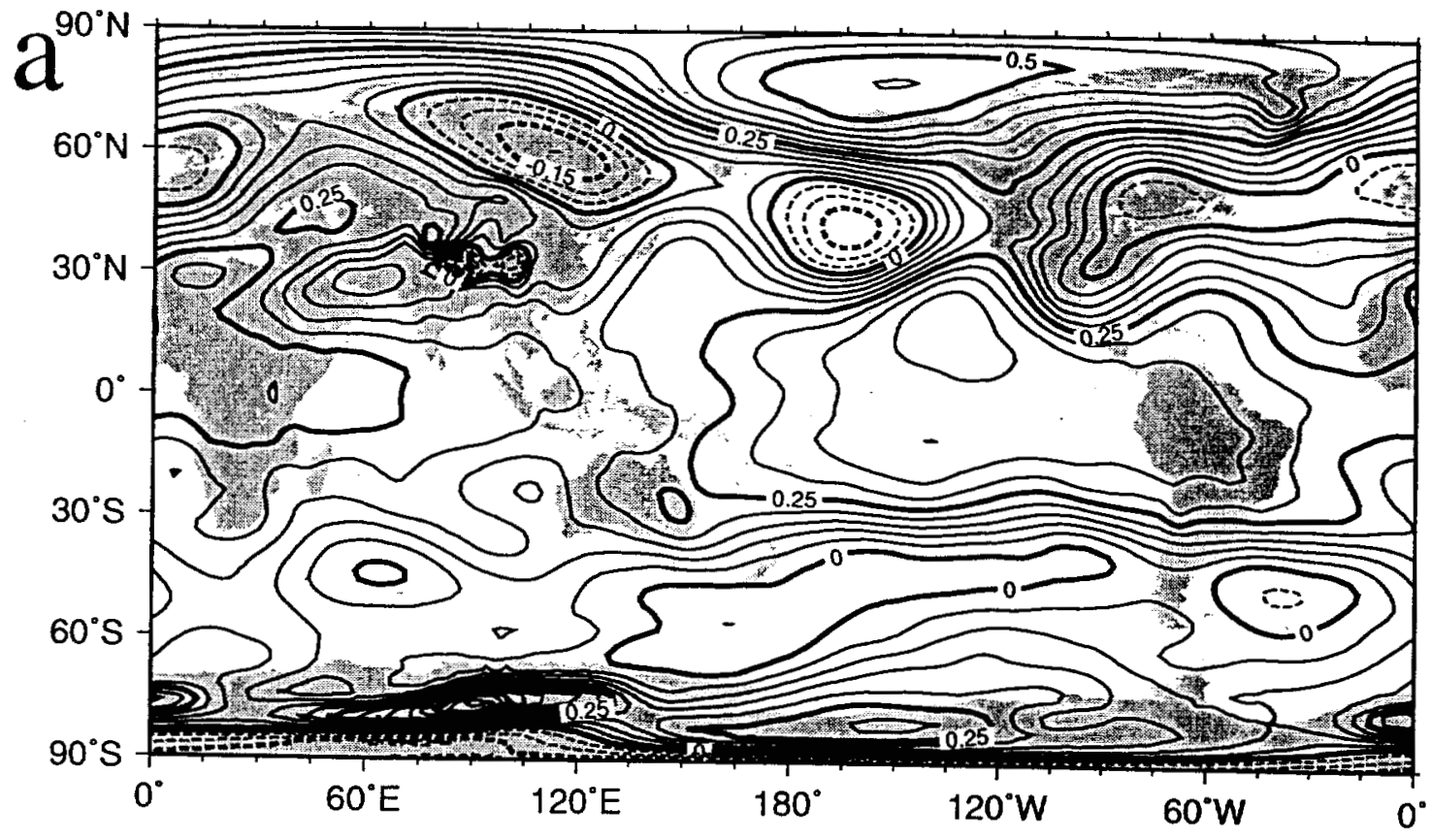

Figure 9 (a), (b)

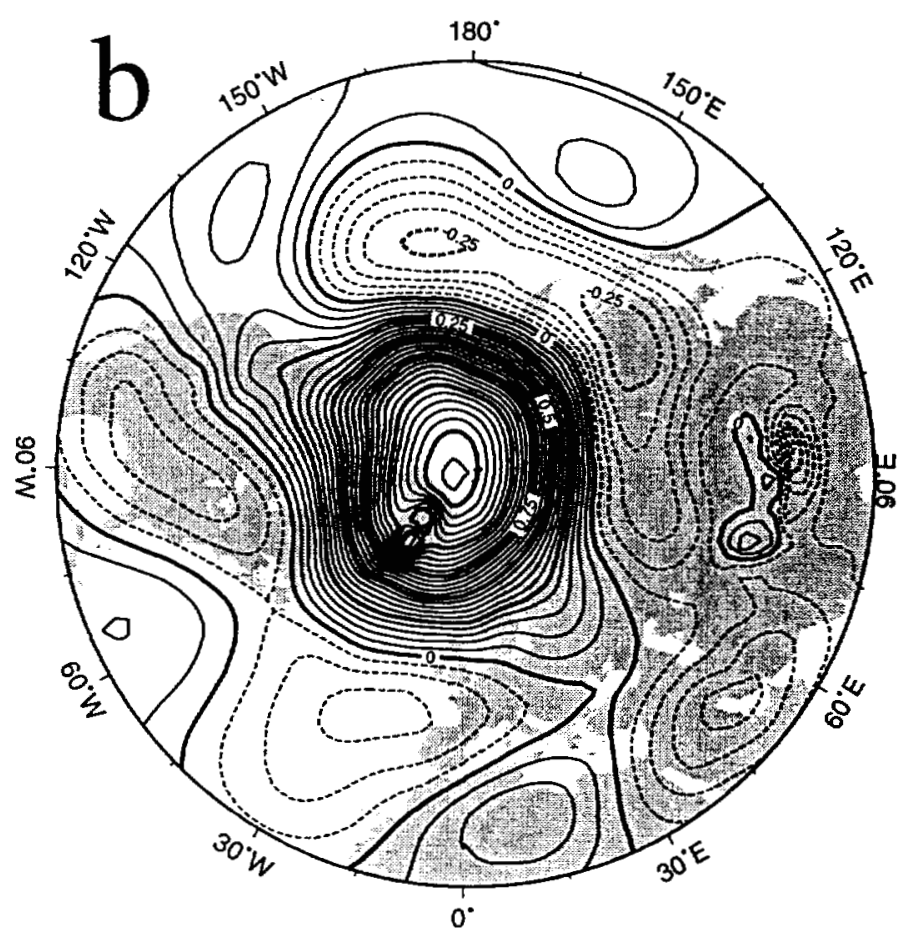




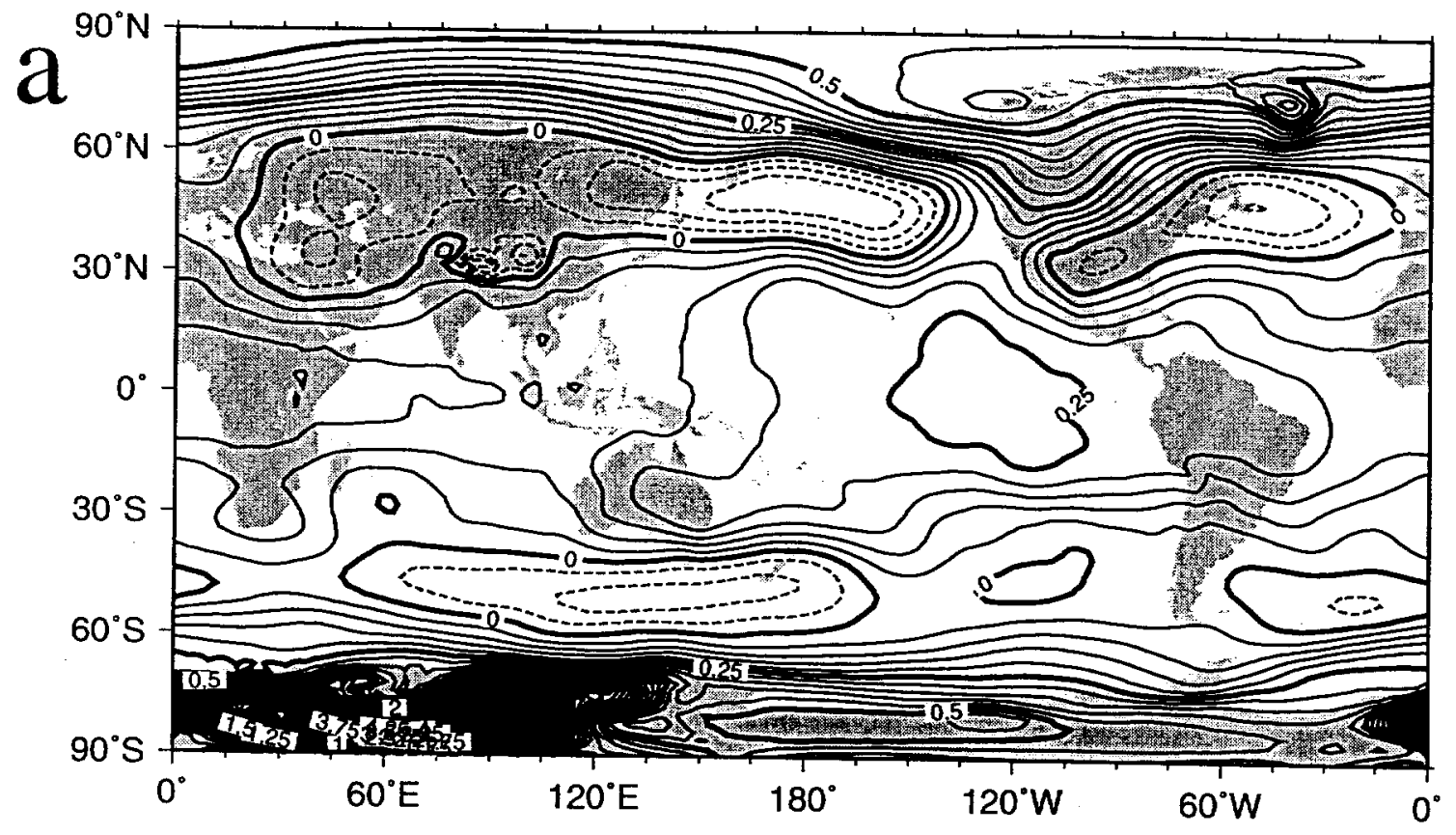

Figure 10 (a), (b)

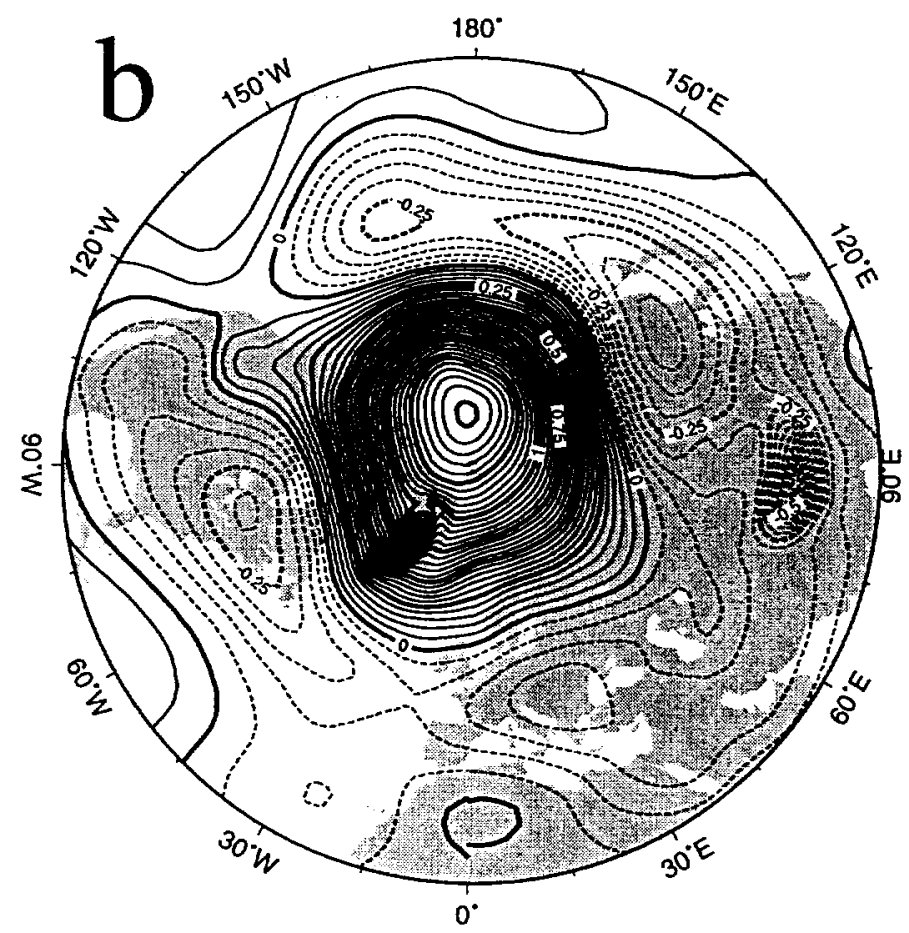




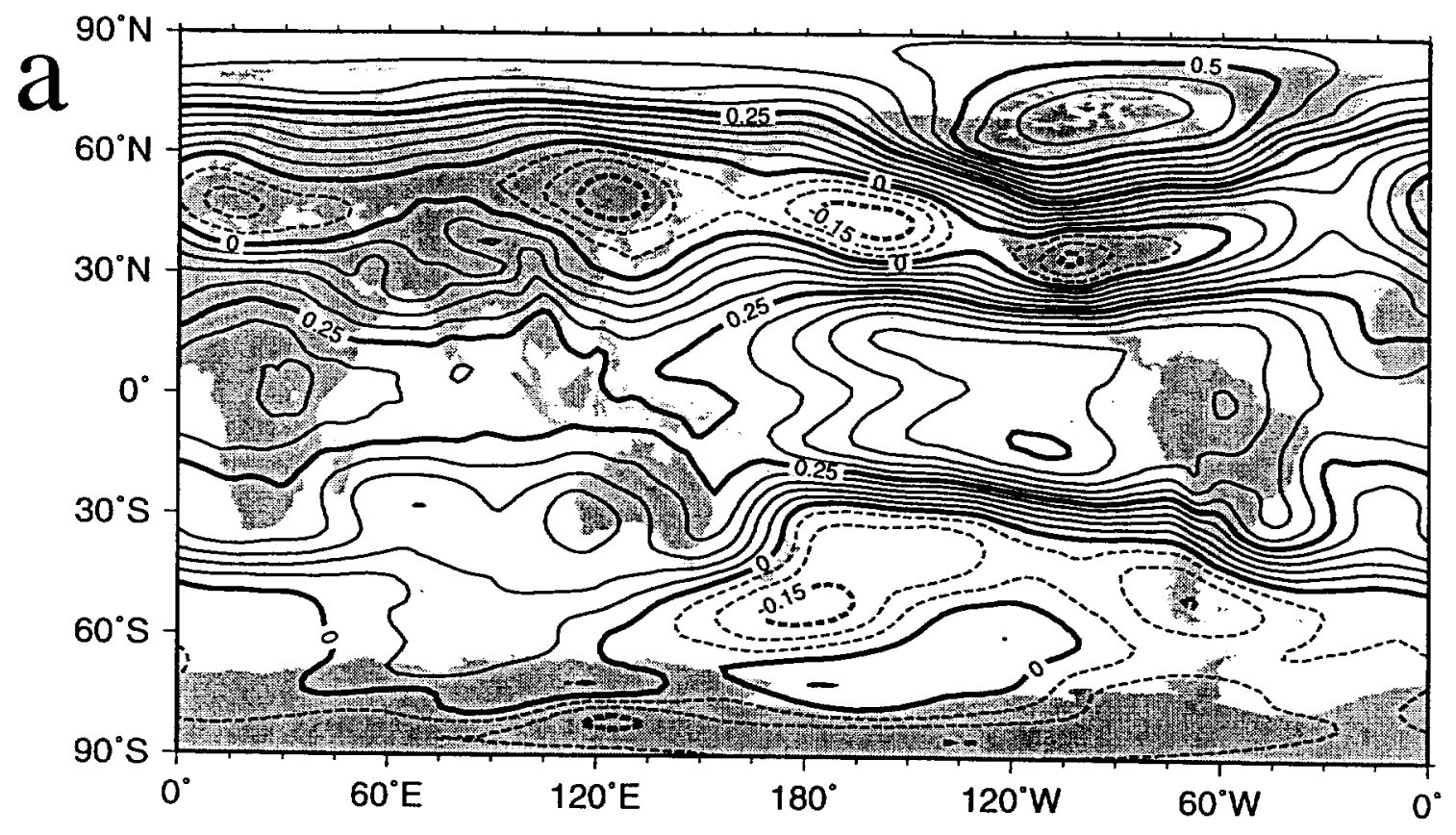

Figure 11 (a), (b)

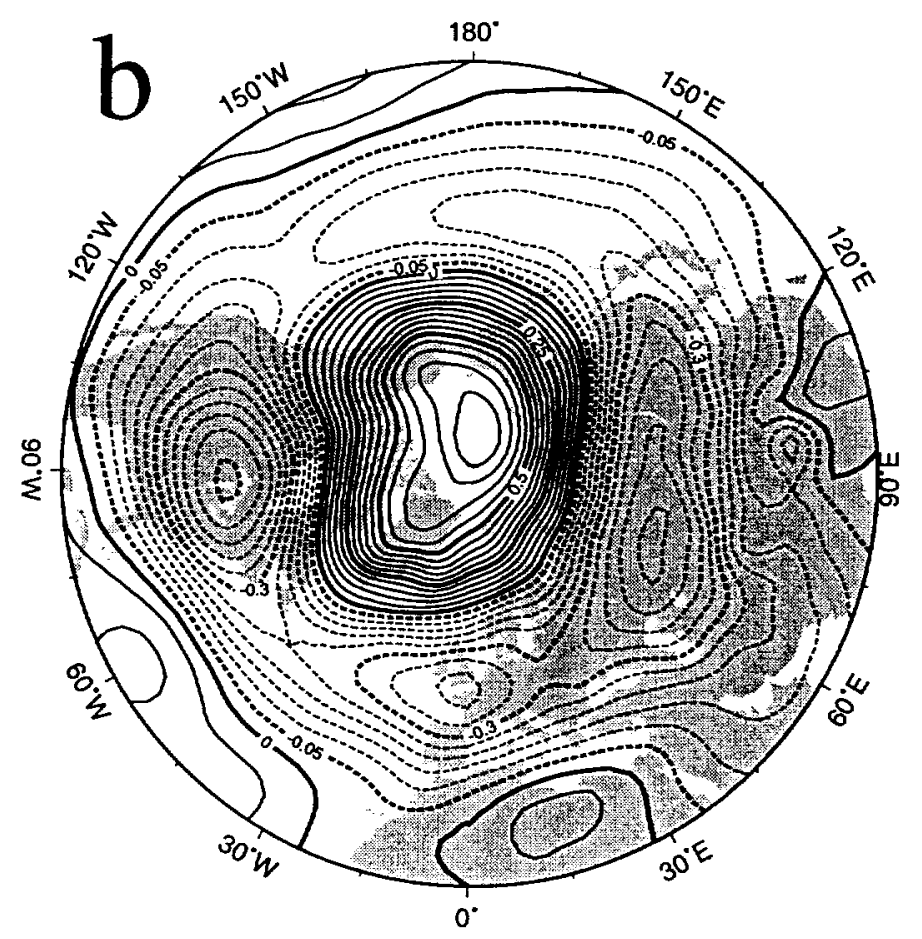




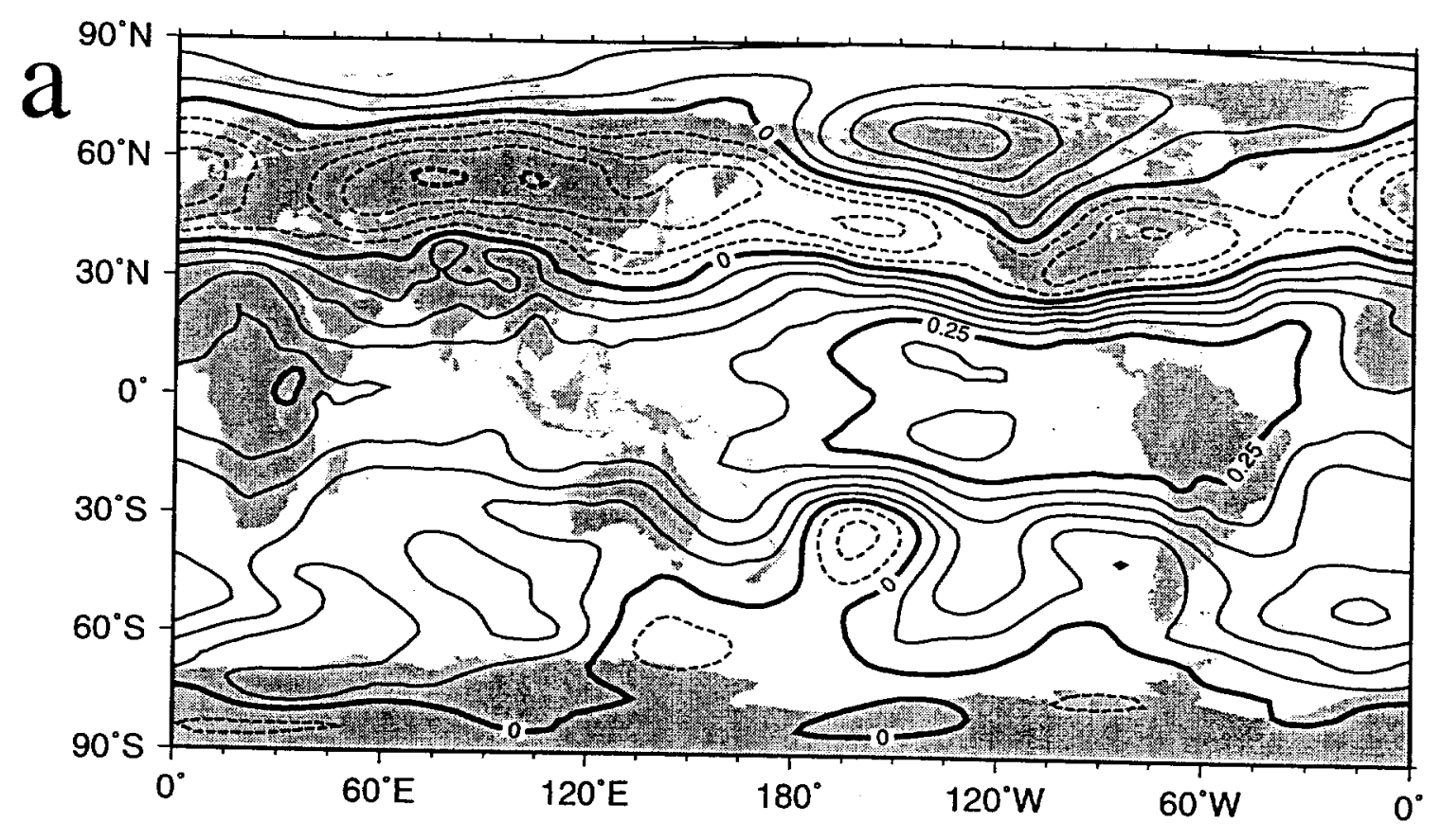

Figure 12 (a), (b)

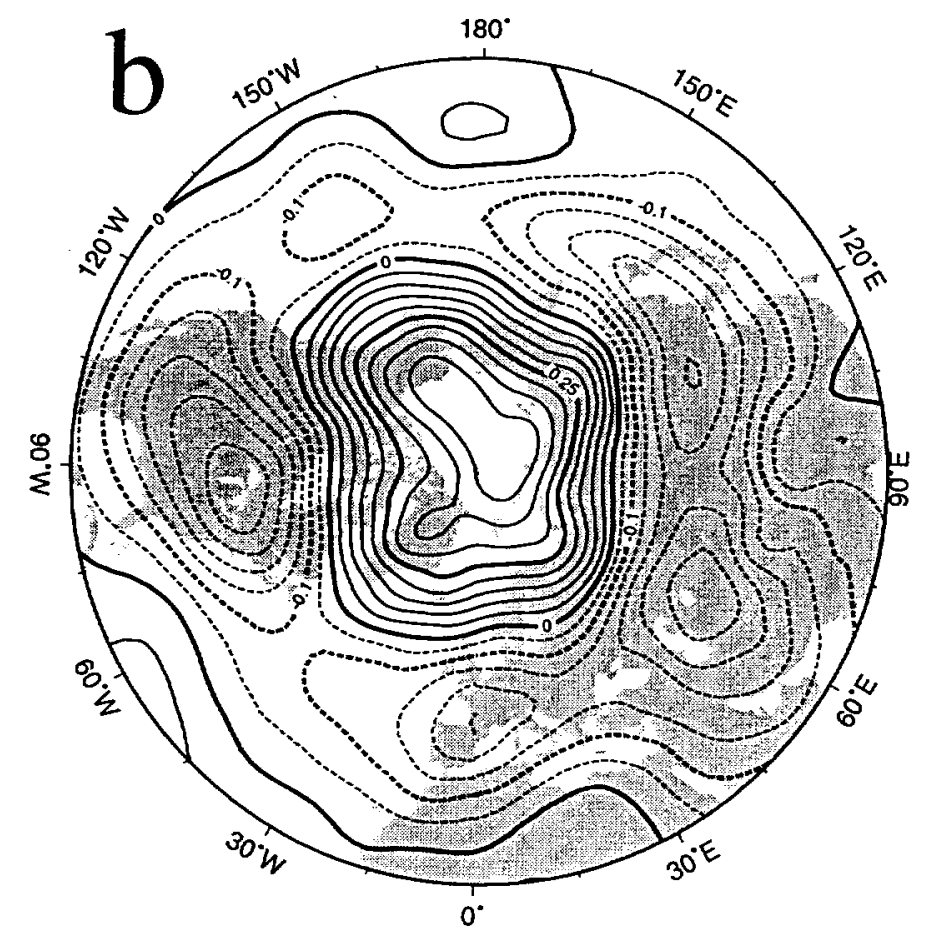



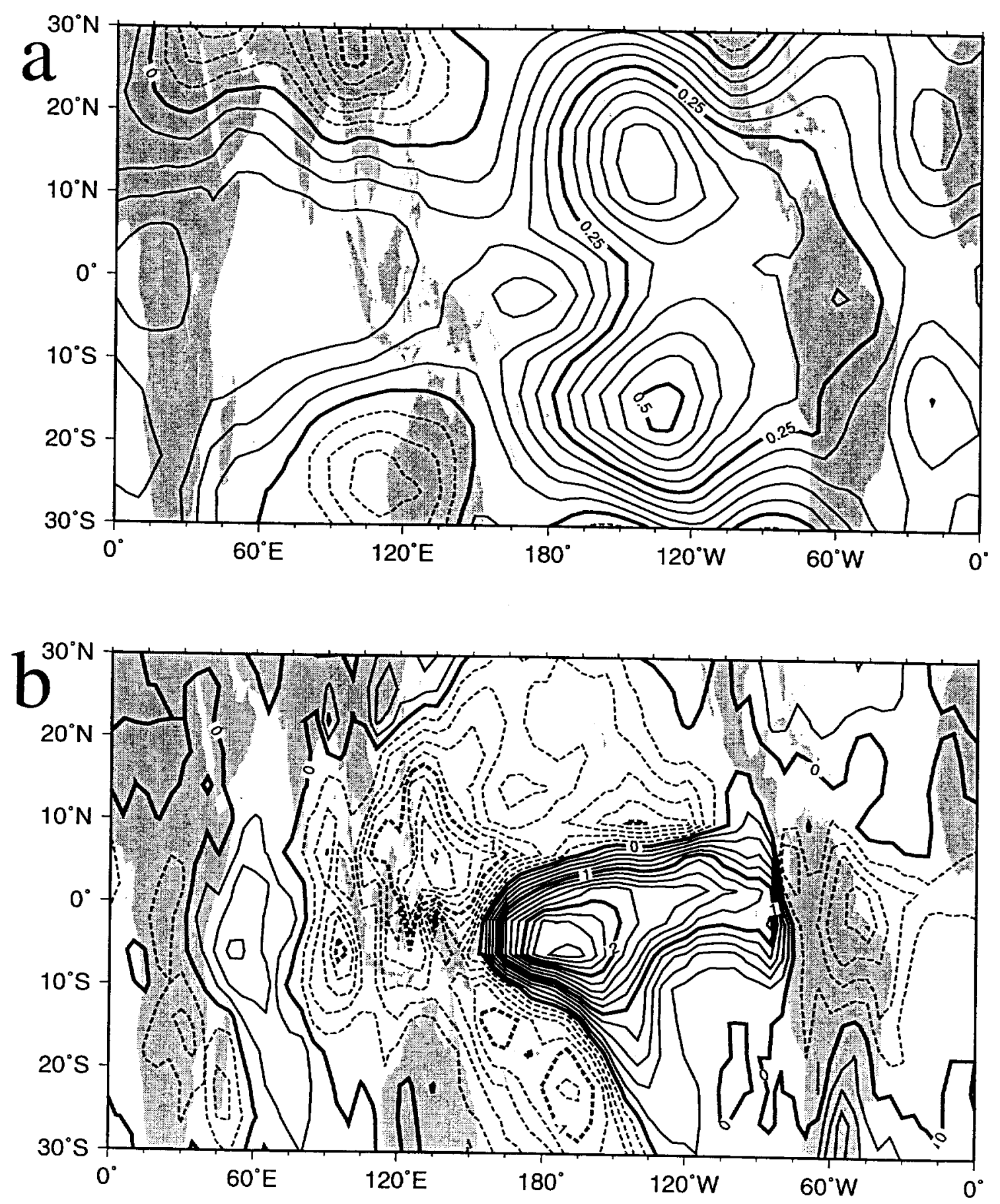

Figure 13 (a), (b) 

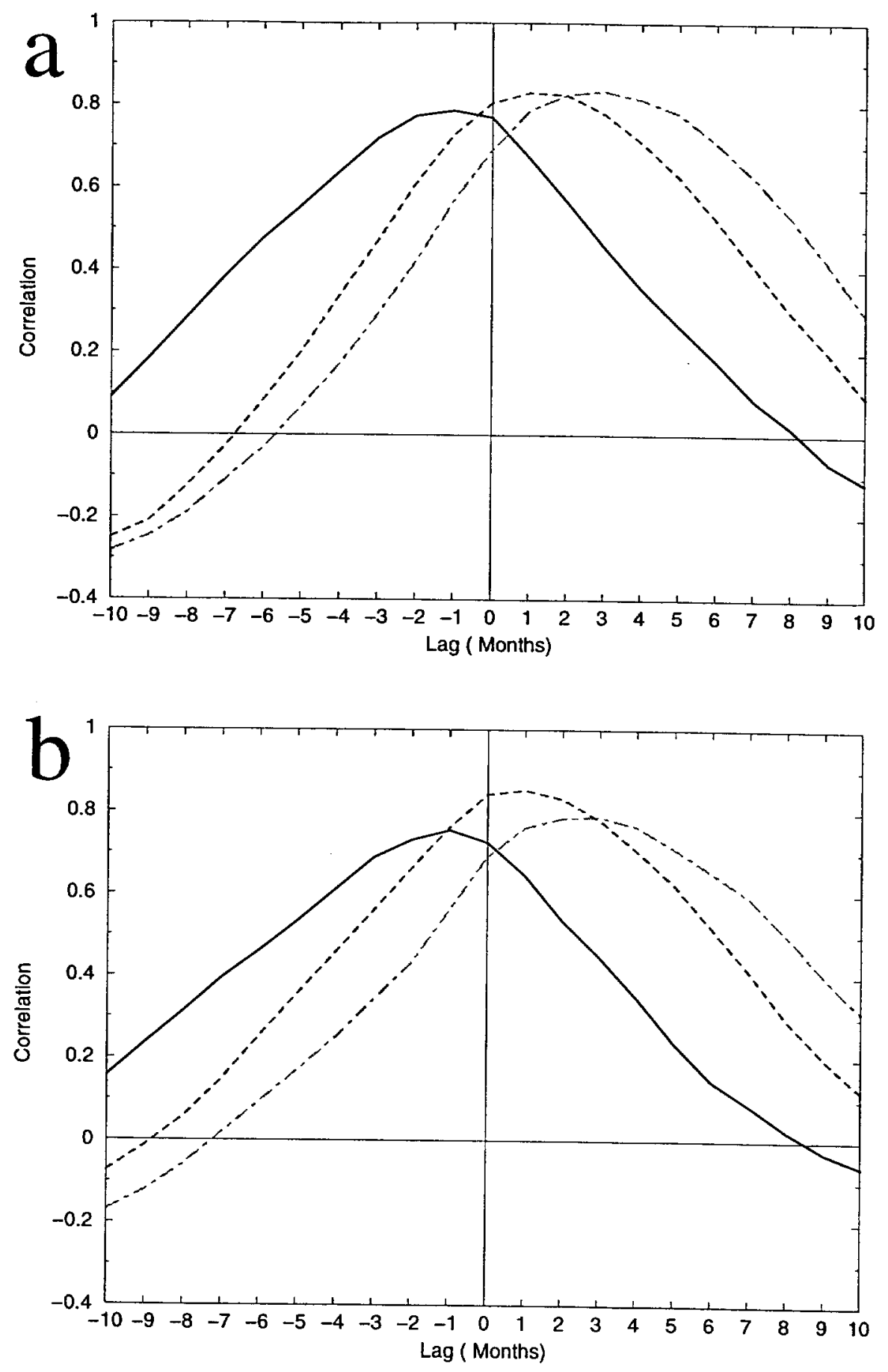

Figure 14 (a), (b) 

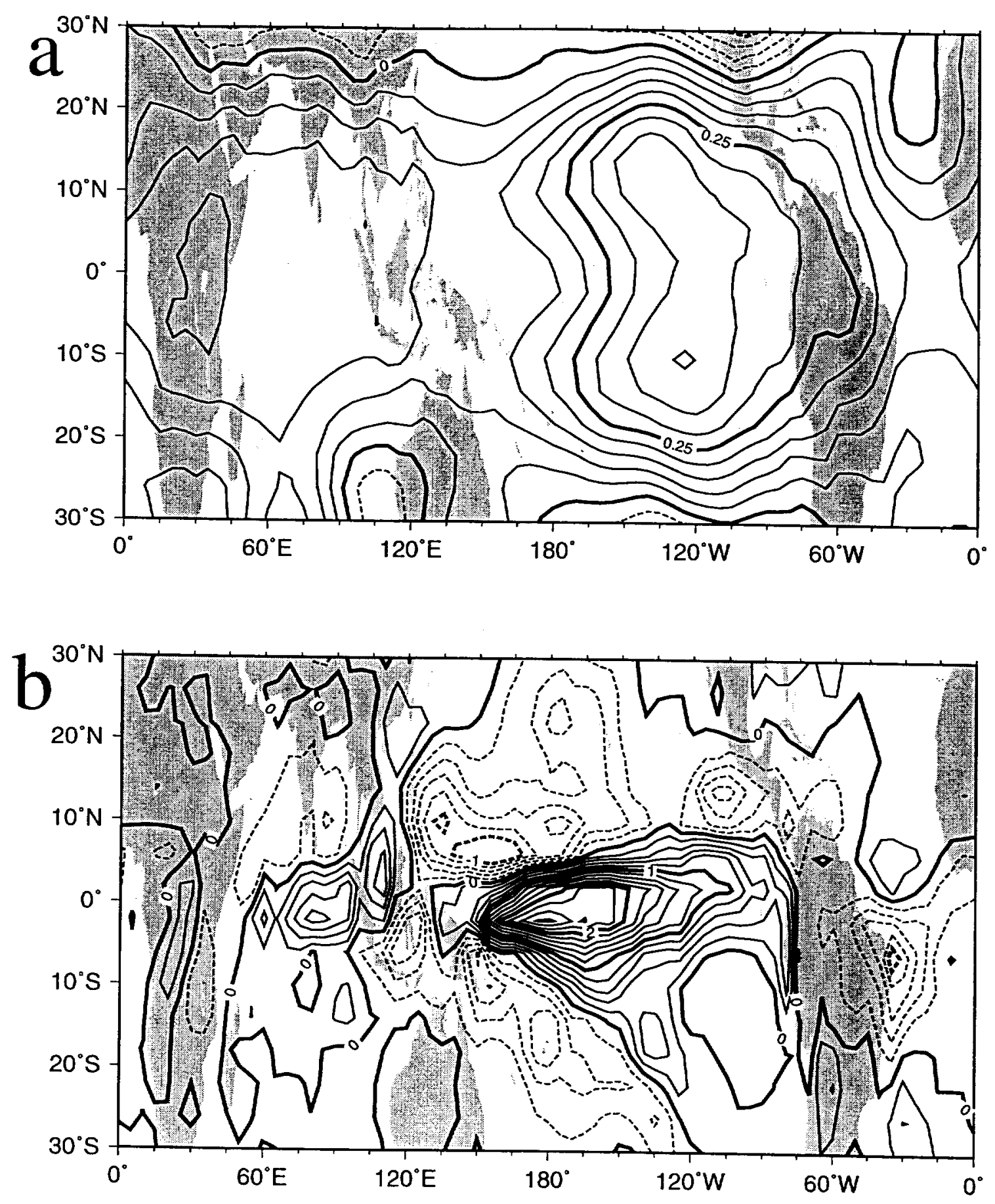

Figure 15 (a), (b) 

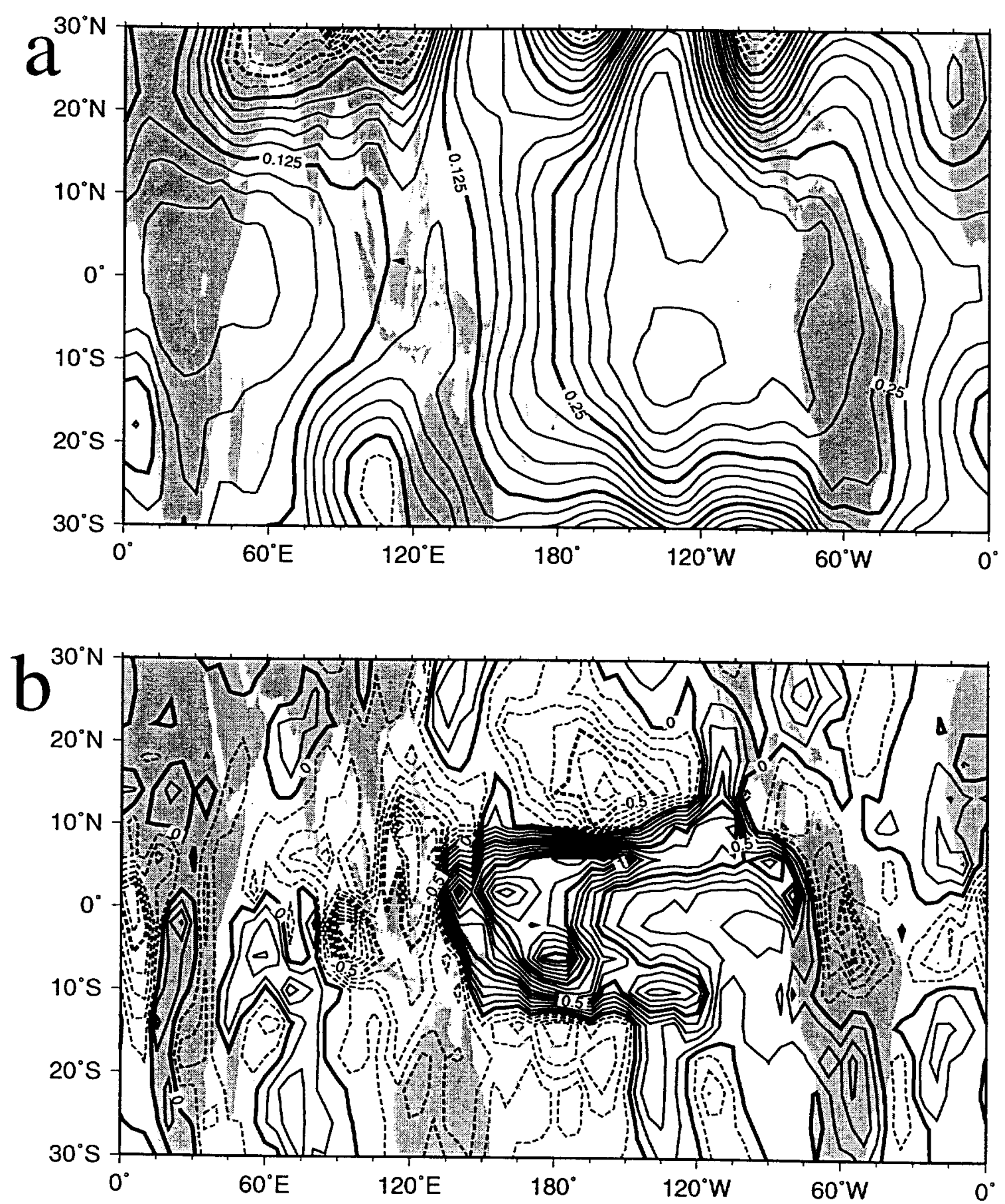

Figure 16 (a), (b) 

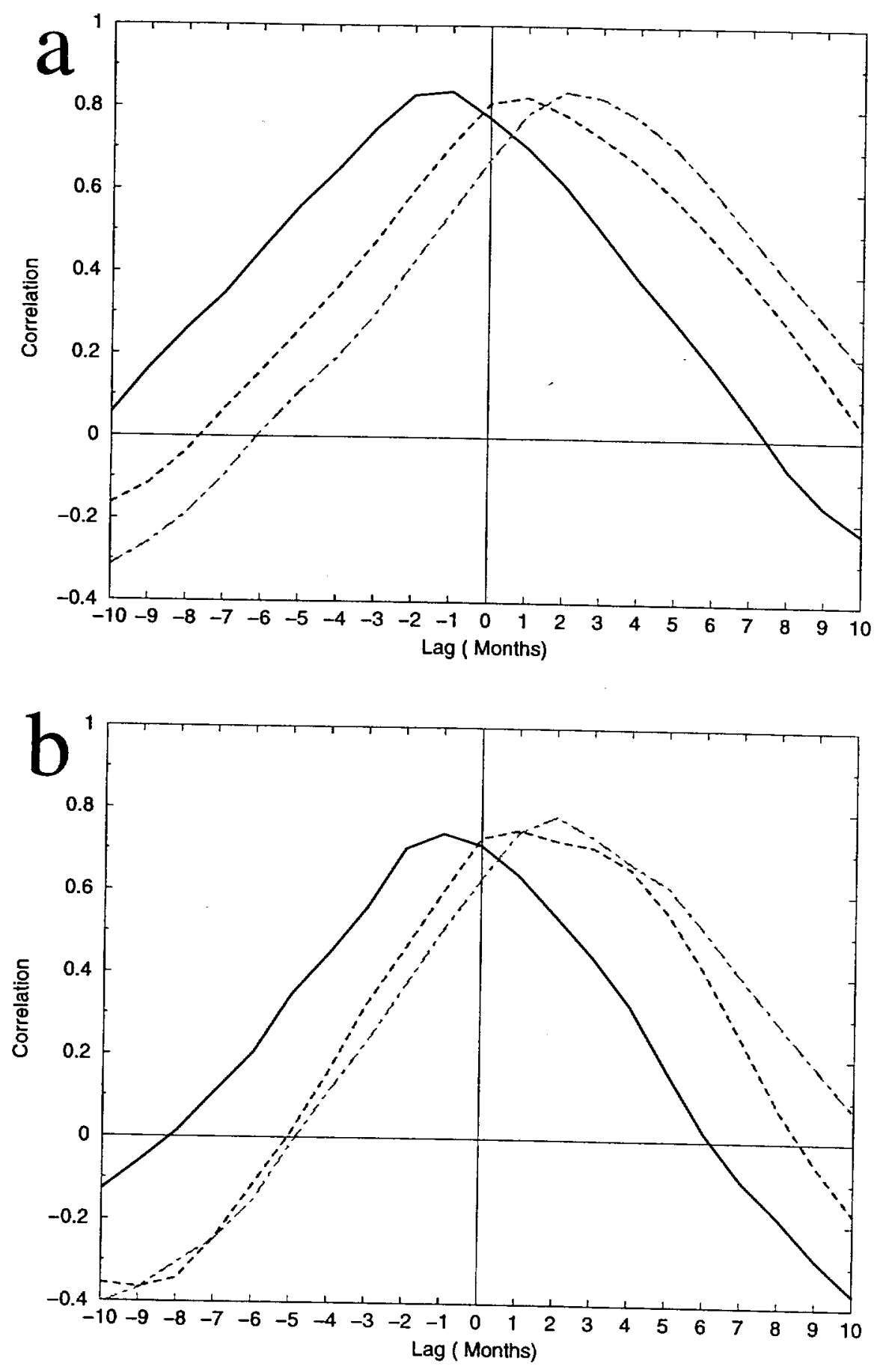

Figure 17 (a), (b) 

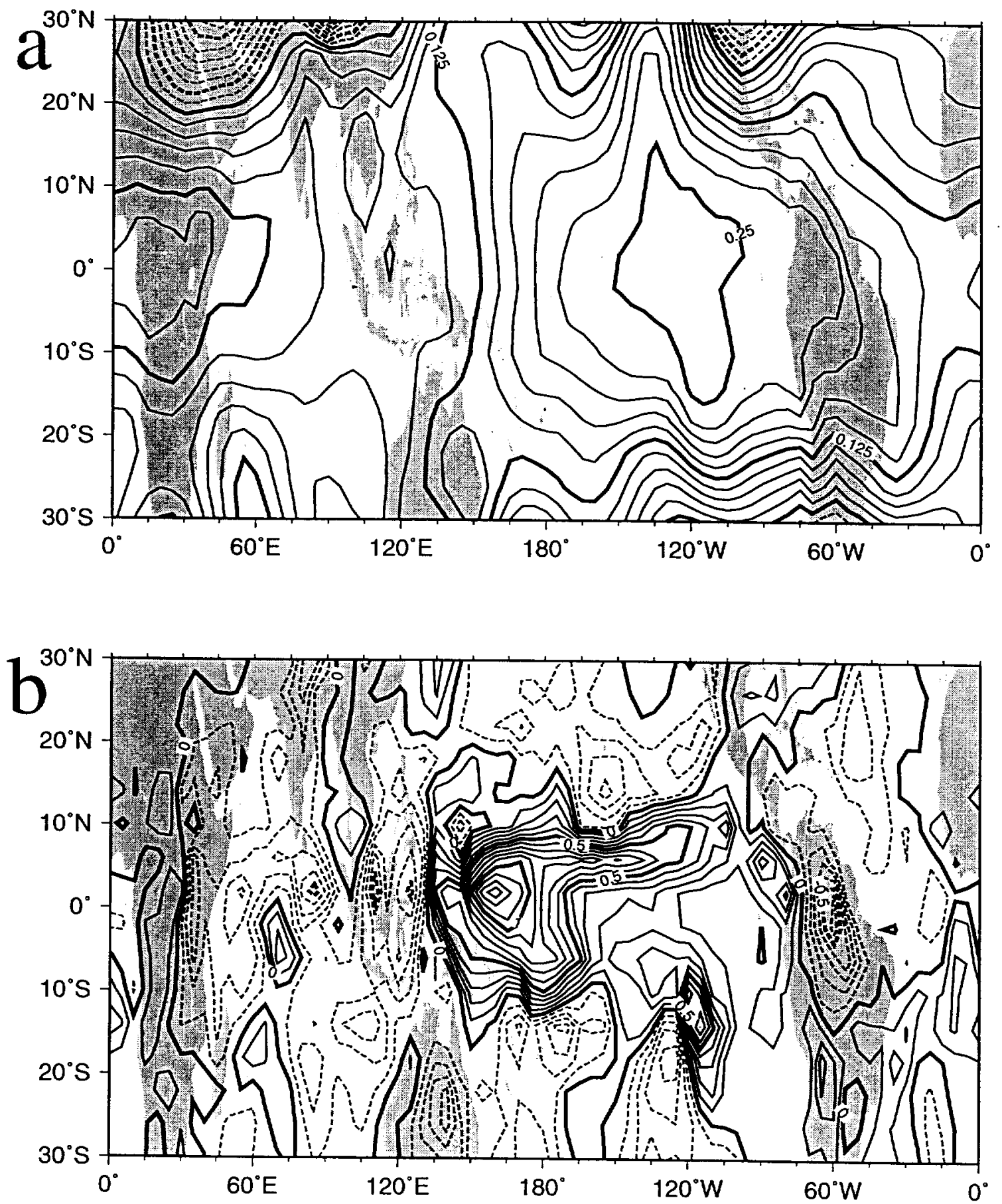

Figure 18 (a), (b) 
(q) '(e) 6 I อ.มถรี!
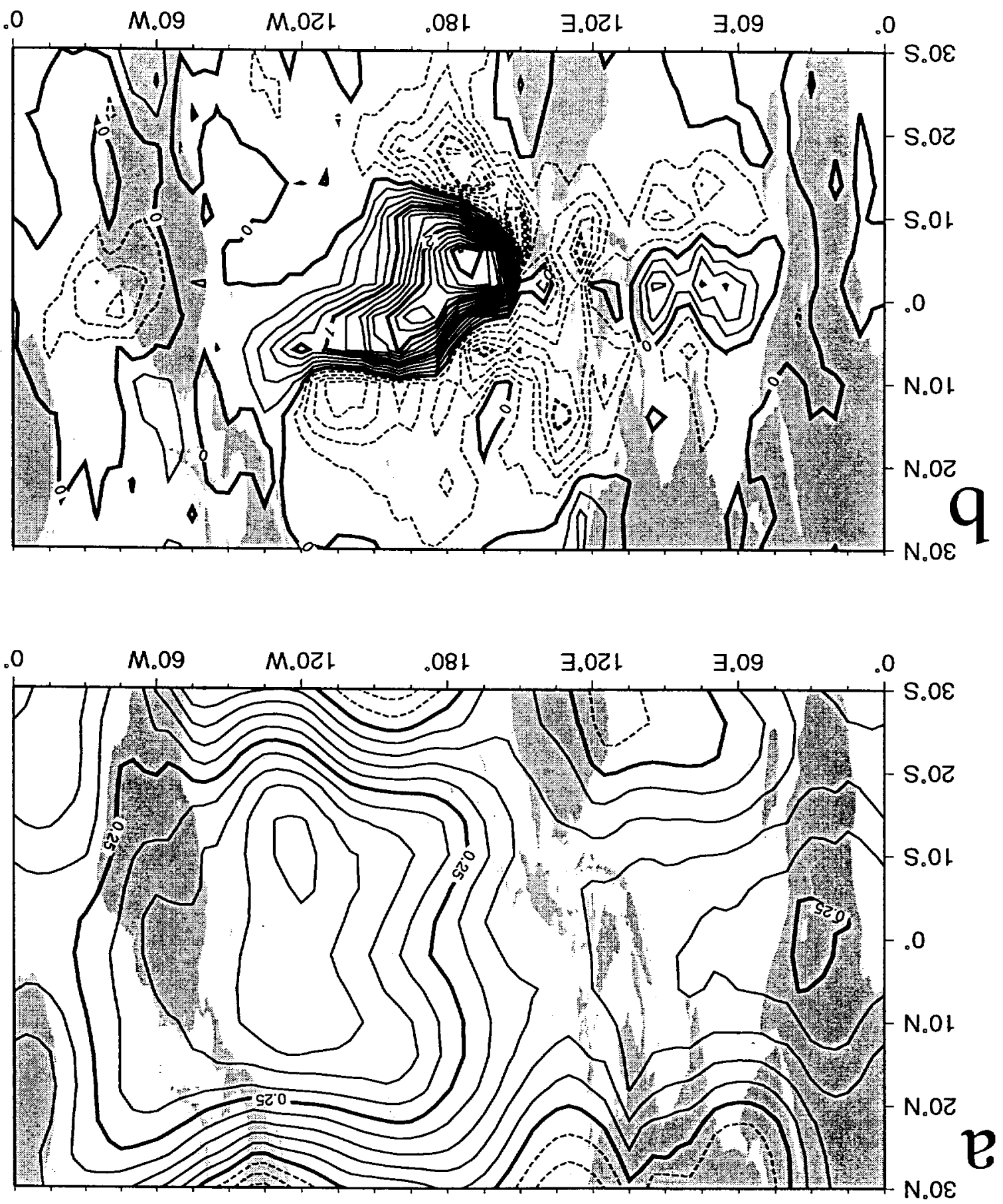

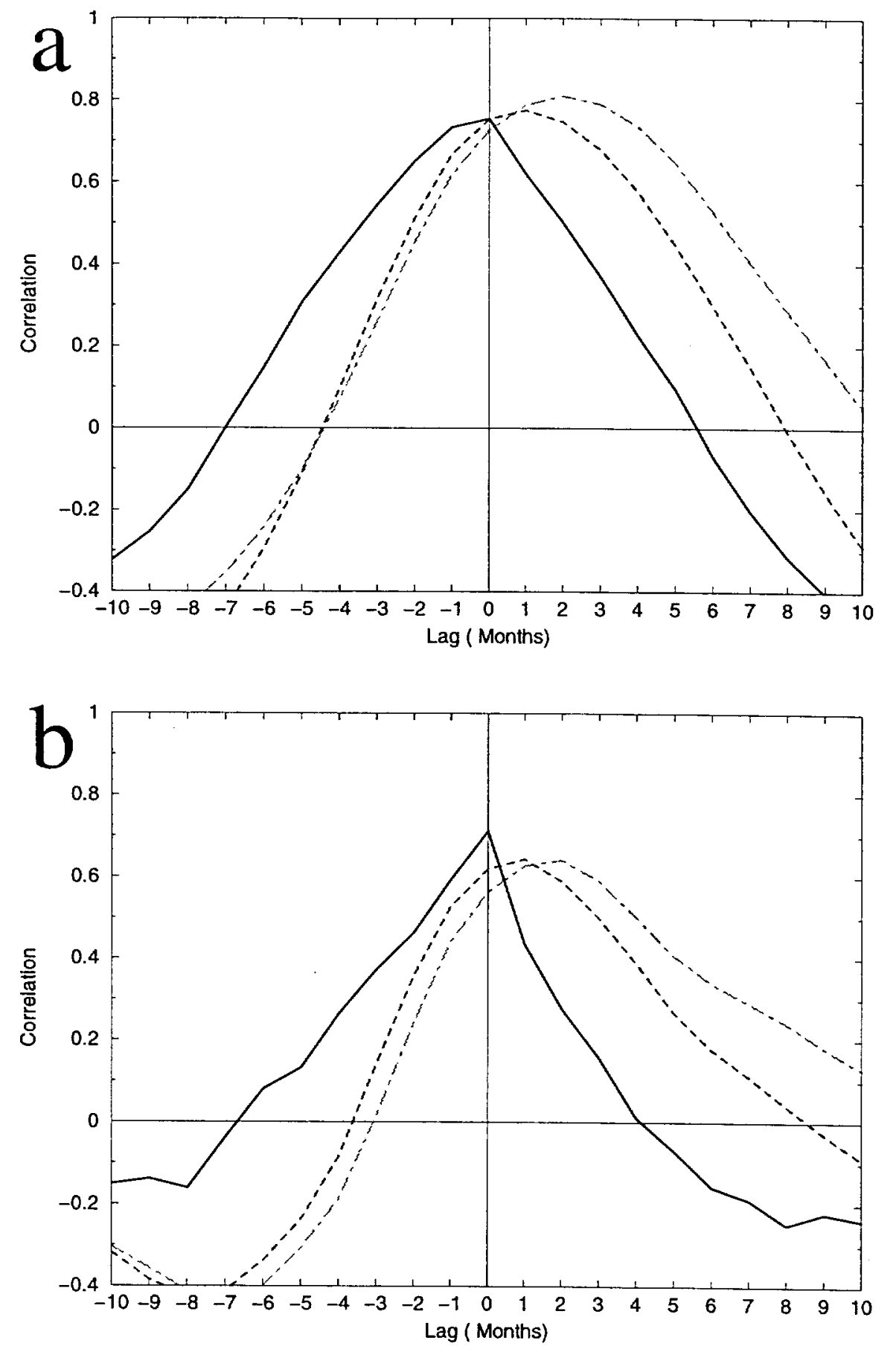

Figure 20 (a), (b) 

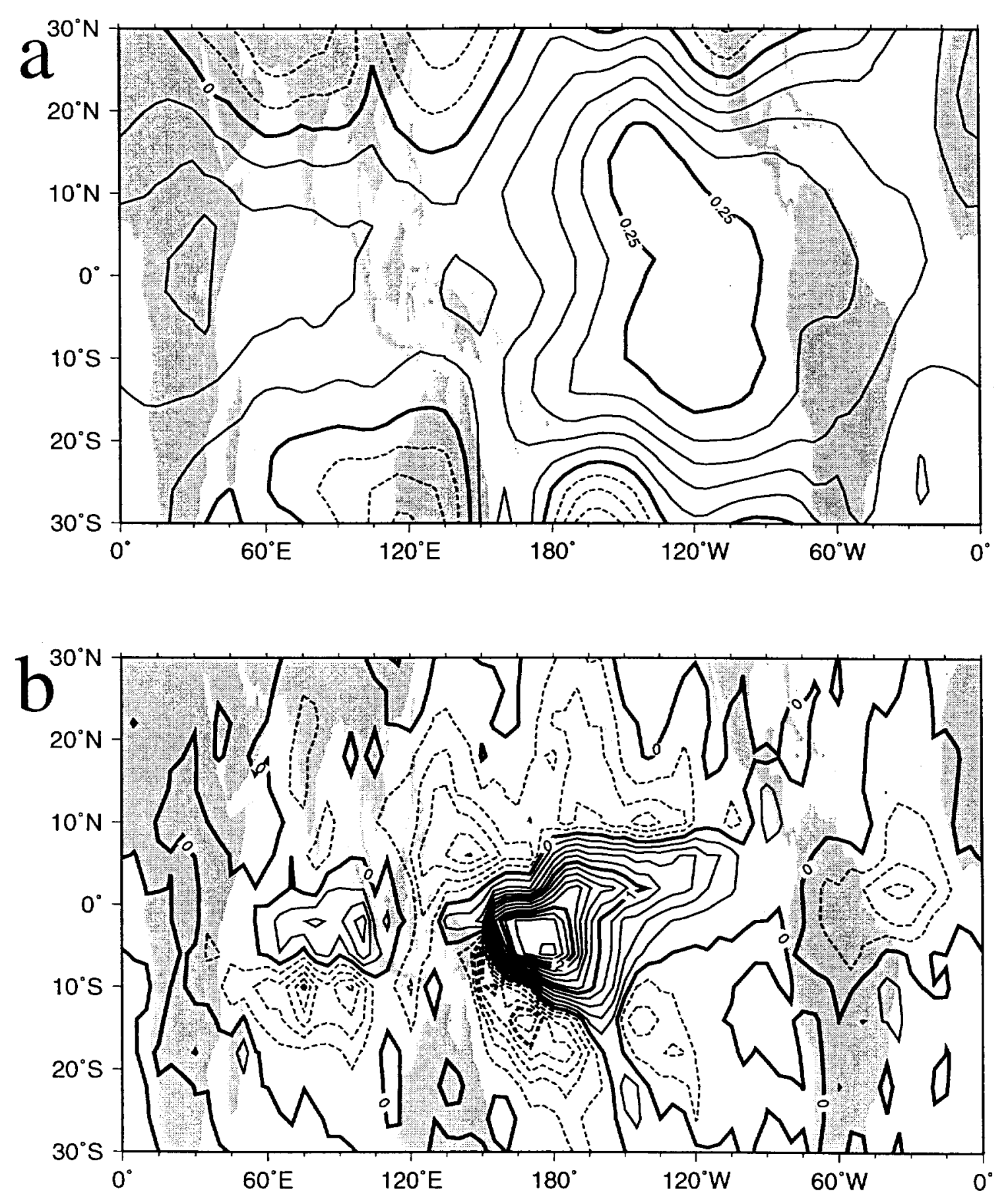

Figure 21 (a), (b) 